\title{
The Functions of Postpartum Depression
}

\author{
Edward H. Hagen \\ Department of Anthropology, University of California, Santa Barbara, California
}

\begin{abstract}
Evolutionary approaches to parental care suggest that parents will not automatically invest in all offspring, and they should reduce or eliminate investment in their children if the costs outweigh the benefits. Lack of paternal or social support will increase the costs born by mothers, whereas infant health problems will reduce the evolutionary benefits to be gained. Numerous studies support the correlation between postpartum depression (PPD) and lack of social support or indicators of possible infant health and development problems. PPD may be an adaptation that informs mothers that they are suffering or have suffered a fitness cost, which motivates them to reduce or eliminate investment in offspring under certain circumstances, and that may help them negotiate greater levels of investment from others. PPD also appears to be a good model for depression in general. () 1999 Elsevier Science Inc.
\end{abstract}

KEY WORDS: Postpartum depression; Parental investment; Life history theory; Evolutionary psychology; Reproduction; Mental health.

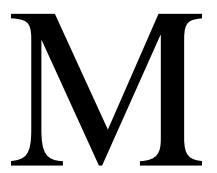
others with postpartum depression (PPD) commonly have thoughts of harming their children, exhibit fewer positive emotions and more negative emotions toward them, are less responsive and less sensitive to infant cues, less emotionally available, have a less successful maternal role attainment, and have infants that are less securely attached (Beck 1995, 1996b; Cohn et al. 1990, 1991; Field et al. 1985; Fowles 1996; Hoffman and Drotar 1991; Jennings et al. in press; Murray 1991; Murray and Cooper 1996). Although most researchers view PPD as a disorder, evolutionary theorists frequently have argued that there are circumstances when it would be in the mother's fitness interest to reduce or eliminate her investment in her offspring, for example, when there

Received April 23, 1998; revised June 15, 1999.

Address reprint requests and correspondence to: Edward H. Hagen, Department of Anthropology, University of California, Santa Barbara, CA 93106,U.S.A. E-mail: hagen@ sscf.ucsb.edu 
is insufficient social support to raise the infant, or when the infant has low viability (Clutton-Brock 1991; Daly and Wilson 1984, 1988; Hrdy 1979, 1992; Trivers 1974).

PPD is a depressive episode with onset occurring one month postpartum (APA 1994). ${ }^{1}$ Depressive episodes are characterized by a number of symptoms including depressed or sad mood, marked loss of interest in virtually all activities, significant weight loss or gain, insomnia or hypersomnia, psychomotor agitation or retardation, fatigue or loss of energy, feelings of worthlessness or guilt, diminished ability to think or concentrate, and recurrent thoughts of death (APA 1994). A diagnosis of a DSM IV major depressive episode requires that five of these symptoms be present during a two-week period, and that at least one of the symptoms is either depressed or sad mood, or a markedly diminished interest or pleasure in all or almost all activities.

Three correlates of PPD are consistently found by researchers: marriage problems and lack of social support, particularly the father's (Table 1), infant problems, including pregnancy and delivery problems (Table 2), and a prior history of depression or other emotional problems (Atkinson and Rickel 1984; Cutrona and Troutman 1986; Gotlib et al. 1991; Graff et al. 1991; Logsdon et al. 1994; O'Hara et al. 1983, 1984; Whiffen 1988; Whiffen and Gotlib, 1993). This paper will propose three related adaptive functions for PPD that are consistent with the expectations of evolutionary theorists and the first two correlates noted above. First, negative affect-i.e., sad or depressed mood—should be associated with social circumstances that were reproductively costly in ancestral environments (e.g., lack of social support or infant problems). This "psychological pain" hypothesis (Alexander 1986; Nesse 1991; Nesse and Williams 1995; Thornhill and Thornhill 1989, 1990; Tooby and Cosmides 1990) is strongly supported by existing evidence. Second, mothers will take actions to reduce their levels of psychological pain, thereby reducing their reproductive costs. This hypothesis is also well supported by existing evidence.

The third hypothesis applies to major rather than minor PPD. A minor form of PPD involving fewer and less severe symptoms is sometimes distinguished from PPD involving a major depressive episode. ${ }^{2}$ Minor PPD is consistent with the psychological pain hypothesis and the two proposed functions described earlier. Symptoms of major PPD not well accounted for by the psychological pain hypothesis-e.g., marked loss of interest in virtually all activities, psychomotor retardation, significant weight loss, diminished ability to think or concentrate, and recurrent thoughts of death-may enable the mother to negotiate greater levels of social support, the third functional hypothesis. In the same way that a valuable employee may attempt to negotiate a larger salary by threatening to quit, mothers receiving insufficient so-

\footnotetext{
${ }^{1}$ The one-month criterion established by the American Psychiatric Association is obviously somewhat arbitary and is meant to distinguish PPD from the far more common, less severe, and transitory blues experienced by two thirds of all mothers in the first 1-2 weeks postpartum. The relationship between PPD and the blues in not clear. PPD is also distinguished from postpartum psychosis, a rare and extreme set of symptoms involving delusions and hallucinations.

${ }^{2}$ Virtually all studies of PPD rely on either clinical diagnosis according to the criteria in the Diagnostic and Statistical Manual (DSM), International Classification of Diseases (ICD), or on depression instrument scores (e.g., Edinburgh Postnatal Depression Scale, Cox et al. 1987) representing a continuum of severity. Minor PPD is usually not diagnosed separately, but is defined by establishing a lower cutoff for a self-report score, or for number of symptoms reported.
} 
cial support may attempt to negotiate larger levels of support by threatening to defect from (i.e., quit) the childrearing endeavor. This hypothesis cannot be adequately tested with the data that are currently available and it is justified on purely theoretical grounds; as such, it is quite speculative.

Because each of these hypotheses involves either an aspect of a mother's decision to invest in or defect from childrearing, or her attempt to negotiate larger levels of support by threatening to defect from childrearing, I will refer to them collectively as the defection hypothesis for PPD. The defection hypothesis, its theoretical foundations, and supporting data will be presented in detail in the following sections. These data are not sufficient to prove the defection hypothesis, however. Other interpretations of the data are possible, and I consider it well beyond the scope of the paper to analyze these other interpretations (there is no consensus on the correct theoretical approach to PPD; see Affonso (1984), Cutrona (1982), and Hopkins (1984) for brief reviews of psychodynamic, personality, cognitive-behavioral, and biophysical theories of PPD. See Cramer (1993), Collins et al. (1993), Cutrona (1983), Cutrona and Troutman (1986), Gotlib et al. (1991), O'Hara et al. (1982), and O'Hara et al. (1984) for experimental tests of particular theories of PPD).

\section{THEORETICAL FOUNDATIONS}

\section{Parental Investment Theory}

The close association of PPD with child bearing and rearing suggests that the application of parental investment (PI) theory may be quite fruitful (see, e.g., CluttonBrock 1991). PI theory, an aspect of life-history theory, provides the evolutionary framework for nearly 20 years of research into parental investment in offspring for both humans (Betzig et al. 1988; Blurton-Jones 1989; Borgerhoff Mulder 1989; Chisholm 1993; Daly and Wilson 1984, 1988; Dickemann 1979, 1981; Draper and Harpending 1982; Hagen 1996, 1998c; Haig 1993; Hartung 1982, 1985; Hill and Kaplan 1988; Hrdy 1992; Lampert and Friedman 1992; Voland 1984) and other species (the literature is huge; for recent syntheses see Clutton-Brock 1991; Roff 1992; and Stearns 1992).

Both PI theory and life-history theory (of which PI theory is a part) form the basis of this functional analysis of PPD. To briefly review, life-history theory posits that in order to have left descendants, the ancestors of any species must have solved the problems of survival, growth, development on the one hand, and reproduction on the other. Because each of these problems is characterized by unique difficulties, and because time, energy, and resources are finite, organisms must optimally allocate these commodities between somatic effort (growth, development, and maintenance of the organism), and reproductive effort (producing offspring who themselves survive to reproductive age).

Reproductive effort, in turn, should be optimally allocated between mating effort (locating and acquiring a mate), and parenting effort (e.g., gestation and raising of offspring) — what I have here termed parental investment in order to be consistent with existing literature (see Clutton-Brock 1991, p. 8, for a discussion of terminol- 
Table 1. Studies that Found a Correlation between Social Support and Marriage Variables and Postpartum Depression

\begin{tabular}{|c|c|}
\hline Study & Correlate of PPD \\
\hline \multicolumn{2}{|l|}{ Emotional support } \\
\hline Affonso and Arizmendi 1986 & Inadequate emotional support \\
\hline Campbell et al. 1992 & Inadequate emotional support* \\
\hline O’Hara 1983 & Less emotional support from confidants* \\
\hline O’Hara 1983 & Less emotional support from mom* \\
\hline O’Hara 1983 & Less emotional support* \\
\hline O’Hara 1986 & Inadequate emotional support* \\
\hline Richman et al. 1991 & Inadequate emotional support \\
\hline Richman et al. 1991 & Inadequate intimacy \\
\hline Richman et al. 1991 & Inadequate reassurance \\
\hline \multicolumn{2}{|l|}{ Instrumental support } \\
\hline Campbell et al. 1992 & Less help from husband at 2 months* \\
\hline Collins et al. 1993 & Less material support received \\
\hline Collins et al. 1993 & Less satisfaction with material support \\
\hline O’Hara 1983 & Less instrumental support* \\
\hline O’Hara 1986 & Less instrumental support* \\
\hline Paykel et al. 1980 & Less help from husband \\
\hline Richman et al. 1991 & Less practical support \\
\hline \multicolumn{2}{|l|}{ Spousal support } \\
\hline Richman et al. 1991 & Low spouse support \\
\hline Spangenberg and Pieters 1991 & Dissatisfaction with marital support \\
\hline \multicolumn{2}{|l|}{ Communication } \\
\hline O’Hara 1983 & Less communication* \\
\hline Paykel et al. 1980 & Poor communication with husband \\
\hline \multicolumn{2}{|l|}{ Nonspousal support } \\
\hline Cutrona and Troutman 1986 & Low social support \\
\hline Kumar and Robson 1984 & Current problems in relationship with mom* \\
\hline O’Hara 1983 & Confidants less available* \\
\hline Richman et al. 1991 & Lack of father support \\
\hline Richman et al. 1991 & Lack of mother support \\
\hline Richman et al. 1991 & Other \\
\hline Spangenberg and Pieters 1991 & Dissatisfaction with social support \\
\hline \multicolumn{2}{|l|}{ Miscellaneous support } \\
\hline Richman et al. 1991 & Low overall support \\
\hline Trotter et al. 1992 & Lack of "doula" (supporting female) at birth \\
\hline \multicolumn{2}{|l|}{ Marriage } \\
\hline Affonso and Arizmendi 1986 & Poor relationship with baby's father \\
\hline Dimitrovsky et al. 1987 & Poor marital relation \\
\hline Gotlib et al. 1991 & Poor dyadic adjustment* \\
\hline Kumar and Robson 1984 & Marital conflict* \\
\hline Logsdon et al. 1994 & Poor postpartum closeness to husband \\
\hline McGill et al. 1995 & Bad relationship PPD $=31 \%$, not depressed $=4.5 \%$ \\
\hline O’Hara 1983 & Marital problems* \\
\hline Whiffen 1988 & Poor prepartum marital adjustment/mood \\
\hline
\end{tabular}

* Postpartum depression (PPD) assessed by clinical diagnosis; otherwise by self-report.

ogy). PI theory focuses on those aspects of an organism's life-history that are specifically involved with producing and raising offspring.

Life history theorists assume that the physiological and behavioral characteristics of organisms represent an approximate solution to the problem of optimizing the allocation of time, energy, and resources between somatic, mating, and parenting effort, with the particular solution depending on the organism's environmental niche 
Table 2. Studies that Found a Correlation between Infant Quality Variables and Postpartum Depression

\begin{tabular}{|c|c|}
\hline Study & Correlate of PPD \\
\hline \multicolumn{2}{|l|}{ Prenatal and delivery problems } \\
\hline Campbell and Cohn 1991 & Pregnancy and delivery complications* \\
\hline Campbell et al. 1992 & $\begin{array}{l}\text { Minor pregnancy and delivery complications (e.g., elevated blood } \\
\text { pressure, gestational diabetes, prolonged labor)* }\end{array}$ \\
\hline O’Hara 1984 & $\begin{array}{l}\text { Obstetric risk factors (abnormal weight gain during pregnancy, } \\
\text { abnormal uterine size, preeclampsia, significant bleeding, } \\
\text { abnormal presentation, fever in labor, and the presence of } \\
\text { meconium-stained amniotic fluid) accounted for } 19 \% \text { of the } \\
\text { variance in depressive symptomology }\end{array}$ \\
\hline Paykel et al. 1980 & $\begin{array}{l}\text { Subjective stress of pregnancy; Objective rating of labor } \\
\text { complications }\end{array}$ \\
\hline \multicolumn{2}{|l|}{ Postnatal problems } \\
\hline Atkinson and Rickel 1984 & PPD in men predicted by perception that infant was below average \\
\hline Hopkins et al. 1987 & $\begin{array}{l}\text { Infant complications accounted for } 12 \% \text { of variability in depression } \\
\text { scores* }\end{array}$ \\
\hline Kumar and Robson 1984 & Premature baby* \\
\hline Whiffen and Gotlib 1989 & $\begin{array}{l}\text { Mental development at } 2 \text { months; infants more tense, less happy, } \\
\text { and have lower endurance at } 2 \text { months* }\end{array}$ \\
\hline \multicolumn{2}{|l|}{ Unexpected correlations } \\
\hline O’Hara et al. 1982 & PPD associated with less complicated deliveries \\
\hline Paykel et al. 1980 & PPD associated with less complicated deliveries \\
\hline \multicolumn{2}{|l|}{ No correlation } \\
\hline Warner et al. 1996 & $\begin{array}{l}\text { PPD not associated with complicated pregnancy (sampling of } \\
\text { women was not random with respect to pregnancy problems, } \\
\text { which may have affected the results) }\end{array}$ \\
\hline
\end{tabular}

* Postpartum depression assessed by clinical diagnosis; otherwise by self-report.

as well as its evolutionary history. In general, effort allocated to reproduction will decrease an organism's ability to survive, grow, and develop, whereas, conversely, effort allocated to survival, growth, and development will decrease reproduction. Similarly, effort allocated to finding a mate will decrease an organism's ability to invest in offspring, whereas effort invested in offspring will reduce an organism's ability to acquire a mate. If parental investment can only occur at the expense of somatic or mating effort, then parents need to decide, based on current circumstances, whether it is more advantageous to invest finite resources in offspring, mates, or themselves. Investment in new offspring should not be automatic.

A number of straightforward predictions follow from PI theory, two of which will be the focus of this paper. First, when offspring require significant investment from mothers, mothers should assess offspring viability (e.g., health) before providing the investment. Second, when offspring require significant investment from both fathers and mothers in order to survive to reproductive age, mothers should assess the availability of father investment before investing themselves.

There is a correspondence between these two predictions of PI theory, and two widely replicated correlates of postpartum depression, namely the mother's perception of lack of support from the father, and "infant problems," including pregnancy and delivery problems (Tables 1 and 2). While PI theory makes it clear why a mother who has an infant with problems or who is receiving insufficient social sup- 
port will neglect, abandon, or kill her offspring, it does not make clear why these circumstances lead a mother to experience depression. The answer may lie in the link between adaptive problems and consequent adaptive behavior, that is, it may lie in the evolved psychology of the mother.

\section{Evolutionary Psychology}

The functional properties of organisms are called adaptations, and the terms function and adaptation will be used interchangeably in this paper. Briefly, adaptations evolved because they solved the recurring problems of survival and reproduction discussed in the previous section. Hearts, lungs, and eyes are typical examples of adaptations, and each evolved to solve an important problem: hearts circulate nutrients to other tissues in the body, lungs extract oxygen from the atmosphere, and eyes collect visual information from the environment. These organs are recognized as adaptations because the features of each correspond closely to the problems they were intended to solve. This correspondence is called evidence of design. The chambers and dense muscles of the heart are ideally designed for pumping blood, but poorly designed for absorbing large quantities of gaseous oxygen. The numerous cavities of delicate tissue that comprise the lungs are ideally designed for absorbing oxygen, but completely ineffectual for focusing light. In order to solve the many problems involved in reproduction, many adaptations are needed. Any organism can therefore be viewed as a large but finite set of functional components, or adaptations, each of which was designed by natural selection to solve a particular reproductive problem in ancestral environments.

The brain, like the rest of the body, consists of a number of adaptations, with vision, hearing, smell, motor control, and physical pain being obvious examples. Evolutionary psychology is the subfield of evolutionary biology that is attempting to identify the functional components of the brain, often referred to as psychological adaptations (Barkow et al. 1992; Daly and Wilson 1983, 1984; Symons 1979). Like other adaptations, a psychological adaptation can be recognized by evidence of its having been designed by natural selection to solve a particular reproductive problem. For example, physical pain functions to inform an animal that its tissue is being damaged, provides information on the precise location of the damage, motivates the animal to withdraw from the damage-causing circumstances, and conditions the animal to avoid similar circumstances in the future. Each of these capabilities requires a sophisticated organization of the nervous system, and each would have facilitated reproduction of the organism.

In general, psychological adaptations evolved to extract information from the environment that was relevant to reproductive problems, and to then generate behaviors, that, on average, solved these problems. It will be argued here that PPD shows evidence of having been designed by natural selection to solve three important problems of the puerperium, and is therefore not an illness, but an adaptation.

The suggestion that PPD is a functional component of human reproductive decision-making was first made by Daly and Wilson (1988), and Wilson and Daly (1994), who have published extensively on parental cognition in evolutionary per- 
spective (e.g., Daly and Wilson 1980, 1987, 1995). In particular, Wilson and Daly (1994) pointed out that both lack of social support and infant problems were associated with PPD, and that, in accord with evolutionary expectations, PPD disinclined mothers to invest in their offspring. This functional hypothesis for PPD has been further elaborated by Hagen (1996, 1998a, 1998b), and Thornhill and Furlow (1998), and will be explored in detail here.

Before proceeding, it is important to point out that adaptations can operate even though individuals may have no conscious awareness of their function. None of our ancestors had any awareness or understanding of the function of fever, for example. In an attempt to avoid lengthy and awkward sentences, however, I use the words "decide" and "should" to indicate the operation of an adaptation, with no conscious or moral intent implied. For example, the phrase "mothers decide to defect from their infants when ... " is shorthand for "a maternal psychological adaptation to defect from the infant is activated when ...." Similarly, the phrase "mother should defect from their infants when ..." is intended to be shorthand for "mothers who defected from their infants when ..., would have had, on average, a greater number of descendants than those who did not defect."

\section{THE DEFECTION HYPOTHESIS FOR PPD, PART ONE: ASSOCIATION OF NEGATIVE AFFECT WITH CORRELATES OF NET FITNESS COSTS}

This section will specify in greater detail some of the adaptive problems faced by ancestral human mothers, and it will propose one deceptively simple but very important psychological function that would have been necessary to address these problems, namely, that ancestral mothers needed to know when their costs were exceeding their benefits. PPD may, in part, assist the mother in determining whether she is suffering (or has suffered) circumstances that were associated with net fitness costs over evolutionary time. The other two components of the defection hypothesis, that PPD may function to reduce investment by the mother or increase the investment of others, will be discussed in later sections.

\section{Costs of the Puerperium}

The major benefit of bearing an offspring-a reproductively successful childinvolves a substantial investment from the mother. The time, energy, and resources required to successfully rear human infants are enormous, a consequence of the considerable degree of brain growth and development that occurs postpartum (Lancaster 1986). Human offspring are unable to fend for themselves; they require mothers to provide several years of direct care. In addition to direct care, mothers in preindustrial populations provide all the fuel for brain development. Breast feeding is metabolically expensive, and the energetic costs of lactation are actually greater than the energetic costs of pregnancy (Worthington-Roberts et al. 1985). The 36,000 kcal of fat that a female may have stored under ideal conditions is sufficient to pro- 
Table 3. Poor Neonatal Outcome is Associated with "Minor" Pregnancy and Delivery Problems that are strongly Associated with Postpartum Depression*

\begin{tabular}{|c|c|}
\hline Study & Outcome \\
\hline Acien 1996 & $\begin{array}{l}\text { The perinatal mortality rates in breech presentations were more than twice those } \\
\text { of the total number of deliveries in Latin America, and more than three times } \\
\text { the total number in Spain and Portugal. }\end{array}$ \\
\hline Ananth et al. 1995 & $\begin{array}{l}\text { Hypertensive disorders were found to have a strong adverse impact on stillbirth } \\
\text { rates (North Carolina). }\end{array}$ \\
\hline Beischer et al. 1996 & $\begin{array}{l}\text { Gestational diabetes was associated with a significantly higher rate of perinatal } \\
\text { mortality, especially if untreated (Australia). }\end{array}$ \\
\hline $\begin{array}{l}\text { de Courcy-Wheeler } \\
\text { et al. } 1995\end{array}$ & $\begin{array}{l}\text { Small size for gestational age (itself a strong predictor of perinatal mortality) was } \\
\text { significantly associated with proteinuric hypertension (Britain). }\end{array}$ \\
\hline Gupta et al. 1996 & $\begin{array}{l}\text { Twenty percent of babies born through meconium-stained amniotic fluid } \\
\text { (MSAF) suffered severe birth anoxia (lack of oxygen) compared to } 5.6 \% \text { in } \\
\text { the non-MSAF group (India). }\end{array}$ \\
\hline $\begin{array}{l}\text { Hawthorne et al. } \\
1994\end{array}$ & $\begin{array}{l}\text { The perinatal mortality (PNM) in women with gestational glucose intolerance } \\
\text { was } 49.2 \text { of } 1,000 \text { compared to a PNM in the background population of } 11.6 \\
\text { of } 1,000 \text {. The fetal malformation rate was } 17.3 \% \text { for established diabetes, } \\
9.8 \% \text { in gestational glucose intolerance, and } 2.2 \% \text { in the background } \\
\text { population (Britain). }\end{array}$ \\
\hline Omu et al. 1996 & $\begin{array}{l}\text { Despite the economic expenditure of about five times more for hypertensive } \\
\text { women in pregnancy than in controls, both obstetric and neonatal outcome are } \\
\text { still significantly worse in the former (Kuwait). }\end{array}$ \\
\hline Schieber et al. 1994 & $\begin{array}{l}\text { Prematurity, malpresentation, and prolonged labor accounted for significant } \\
\text { proportions of the observed perineonatal mortality (rural Guatemala). }\end{array}$ \\
\hline Scorza 1996 & $\begin{array}{l}\text { Breech presentation is associated with significantly increased risk of perinatal } \\
\text { morbidity and mortality. Most of the morbidity and mortality associated with } \\
\text { breech delivery results from cord compression, entrapment of an arm behind } \\
\text { the head (nuchal arm), and difficulty in the delivery of the aftercoming head. }\end{array}$ \\
\hline Walker 1996 & $\begin{array}{l}\text { Pregnancy-induced hypertension remains the largest cause of maternal death in } \\
\text { the United Kingdom. }\end{array}$ \\
\hline Weiss et al. 1994 & $\begin{array}{l}\text { In unrecognized and hence untreated pregnancies involving gestational diabetes, } \\
\text { perinatal morbidity and mortality are increased } 20 \text {-fold (Germany). }\end{array}$ \\
\hline
\end{tabular}

*See Table 2 and text for details.

vide only about one third of the energy required to support 4 to 5 months of lactation (Widdowson 1976). The typical woman in a preindustrial setting is unlikely to conform to this western ideal, however. She often begins pregnancy with lower nutritional reserves, gains little if any fat during pregnancy, may lactate for more than 3 years, may be subject to special dietary restrictions during lactation, and must provide virtually all of the infant's nutrition for at least the first 6 months postpartum (Wood 1994). Lactation will occur at the expense of maternal stores, and the net effect of these differences is that the nutritional status of women in traditional societies often declines sharply over the course of lactation, a phenomenon referred to as maternal depletion syndrome (Bongaarts and Delgado 1979; Miller and Huss-Ashmore 1989). Nursing an infant can seriously impact the mother's health.

The postpartum period is clearly a very expensive one for the nursing mother, much more so than pregnancy. The decision to invest in the infant is consequently of critical importance, and a necessary functional component of the mother's decision-making process is information on whether her costs are exceeding her benefits.

Many researchers have attempted to identify functions for psychological dis- 
tress, neuroses, and depression that would compensate for their obvious costs (Alexander 1986; Birtchnell 1993; Gardner 1982; Gilbert 1989; Henderson 1974, 1981; McGuire and Troisi 1998; Nesse 1991; Nesse and Williams 1995; Price et al. 1994; Slavin and Kriegman 1992; Thornhill and Thornhill 1989, 1990; Watson and Andrews, unpublished; Wenegrat 1995). Virtually all propose functions involving an adaptive response to varied interpersonal problems. In particular, several of these researchers have proposed that whereas physical pain functions to inform individuals that they have suffered a bodily injury, psychological pain informs individuals that they have suffered a nonbodily injury (sometimes referred to as a "social injury") motivating them to cease activities that would further this injury, as well as to avoid any future situations that also would result in injury (Alexander 1986; Nesse 1991; Nesse and Williams 1995; Thornhill and Thornhill 1989, 1990; Tooby and Cosmides 1990). A nonbodily injury is any circumstance, usually involving relationships with others, that was reliably associated with a reduction in reproductive fitness over evolutionary time, e.g., the death of children and relatives or loss of status.

An important symptom of PPD is a sad or depressed mood (APA 1994). The first and most strongly supported functional hypothesis for PPD offered here is that a sad or depressed mood is information to the mother that she is suffering (or has recently suffered) circumstances that were reliably associated with net reproductive fitness costs over evolutionary time.

\section{Failure to Offset Puerperal Costs: Hypothesized Etiological Factors for PPD}

If PPD functions, in part, to inform mothers that they are suffering or have suffered circumstances that were reliably associated with net reproductive fitness costs, then these circumstances should be important etiological factors for PPD. New mothers have just invested 9 months in the new offspring, and they need to evaluate their decision to get pregnant, decisions made during pregnancy, and whether to continue to invest in the offspring in light of the following circumstances that would have either substantially increased their costs or reduced their benefits (for a similar list see Mann 1992):

1. There is insufficient investment from the father or others to successfully raise the offspring.

2. There are problems with pregnancy, birth, or with the infant that indicate that this offspring may have low viability, that is, is unlikely to survive to reproductive age.

3. Environmental conditions are poor for raising an offspring (e.g., harsh winter, insufficient resources).

4. There are large opportunity costs-investment in the offspring precludes investment in other beneficial activities. In this case, investment directed toward the offspring would be more profitably directed toward:
A. Existing offspring
B. The mother's own survival, growth, and development, and thus her ability to invest in future offspring
C. Finding a better mate. 
During our evolutionary history, investment by others was key to reducing the costs of childrearing and increasing infant viability. Lack of social support, even in populations with access to modern health care, correlated in one study with lower birth weight babies, lower scores on the 5-minute Apgar test (which rates respiratory effect, muscle tone, heart rate, reflex irritability, and skin color 5 minutes after delivery), and labor difficulties (Collins et al. 1993).

Numerous developmental problems can significantly reduce infant viability. Poor neonatal functioning should be associated with negative affect. In addition to obvious infant problems, reliable predictors of infant problems, particularly those predictors that occur prepartum, would be very useful to ancestral mothers attempting to evaluate offspring viability. Pregnancy and delivery problems like gestational diabetes, pregnancy-induced hypertension, and abnormal presentation are significant predictors of high child malformation and mortality rates even when mothers have access to modern medical care (see Table 3; also see footnote 3 for possible confounding factors).

Considering that ancestral mothers did not have access to modern medical technology, pregnancy and delivery problems would have been excellent predictors of lowered infant viability, even in the absence of overt infant defects. Mothers with pregnancy or delivery problems therefore should be more likely to consider defecting from the childrearing venture than those without such problems. If infants have health problems that would have been reliably reversible in ancestral environments, e.g., moderately low birth weight or mild infections, and the resources to deal with such problems, they should increase rather than decrease their investment in the offspring (see Mann 1992 for a discussion of circumstances that should lead to an increase in maternal investment in the infant).

Even when mothers have healthy, happy babies and plenty of social support, there may not be enough resources to successfully raise them. Assuming adequate fat reserves, lactation still requires an additional $500 \mathrm{kcal} / \mathrm{day}$ (Worthington-Roberts et al. 1985). If food is scarce, mothers may not be able to safely provide this resource to new offspring without jeopardizing their own health or the health of existing children.

Finally, it is possible that higher quality long-term mates are available, even if the mother's current mate is willing and able to invest. Potential mates may be healthier or have access to significantly greater resources than the current mate, for example. Logically, "mate quality" is distinct from "investment." However, a father's "mate quality" includes his ability and willingness to invest in the mother and offspring. Because I am aware of no studies that correlate PPD with the availability of potential mates that are healthier or have greater resources, mate quality will, for the purposes of this article, be considered synonymous with ability and willingness to invest. Prediction $4 \mathrm{c}$ about the mother trading-off in the new offspring investment against finding a better mate then reduces to prediction 1 about insufficient paternal investment.

Given that each of these factors should significantly impact mothers' decisions to invest in their infants, they should obviously also be significant etiological factors for affective states that inform those decisions-each of these factors should predict 
PPD. As will be discussed, the evidence that factors 1 and 2 predict PPD is excellent; the evidence that factors 3 and 4 predict PPD is currently limited.

\section{Prevalence of Postpartum Depression versus Nonpostpartum Depression: A Caveat}

The defection hypothesis requires that pregnancy and childbirth are causal factors for PPD. Given that the base rates for depression and depressive symptoms are high among women in community samples, it is not clear that depressions occurring postpartum are anything other than coincidentally related to pregnancy and childbirth, an important issue that is surprisingly understudied.

Whiffen (1992) found the overall rate for PPD of $13.0 \%$ to be approximately double the community rate for nonpostpartum major and minor depression. The comparison of these rates did not control for marital status. The 1-year prevalence rates of major depression in community samples among married women is much lower $(2.1 \%)$ than among divorced women (6.3\%) (Weissman et al. 1991). Because most postpartum women are married, controlling for marital status would likely increase the difference between the baseline rate and the rate postpartum, increasing the probability that PPD is causally related to childbirth.

The best controlled study of prevalence rates (Cox et al. 1993) found no significant differences between postpartum depressed women and women in a control group in either point prevalence at 6 months postpartum or 6-month prevalence rates (see also Campbell and Cohn 1991; O'Hara et al. 1990), but did find that the rate of onset was three times higher for the postnatal group versus the control group within 5 weeks of childbirth. Therefore, the available evidence supports the conclusion that at least some cases of depression postpartum are nonrandomly associated with parturition, although this issue clearly warrants further study.

\section{Tests of the Defection Hypothesis for Postpartum Depression}

Prediction 1: lack of social support should predict negative affect. Lack of "support" from the spouse, family, and others is strongly correlated with PPD, a result that has been replicated in numerous studies. The correlation of lack of spousal support with PPD is virtually undisputed (see Table 1) and holds regardless of whether PPD is assessed by symptom levels from self-report instruments or clinical diagnosis (correlations with clinical diagnoses of PPD are marked with an asterisk in Table 1). The association of PPD with lack of social support is also supported by two metaanalyses (Beck 1996c; O’Hara and Swain 1996).

A causal relationship between marital satisfaction and PPD in women is supported by the study of O'Hara (1985) of depressive symptomology and marital satisfaction in 51 couples. In this study, $18.0 \%$ of the women and $7.8 \%$ of the men had symptoms of at least mild depression at 6 weeks postpartum. The depression and marital satisfaction scores obtained from the husbands at 6 weeks were excellent predictors of their wives' depression and marital satisfaction scores obtained 3 


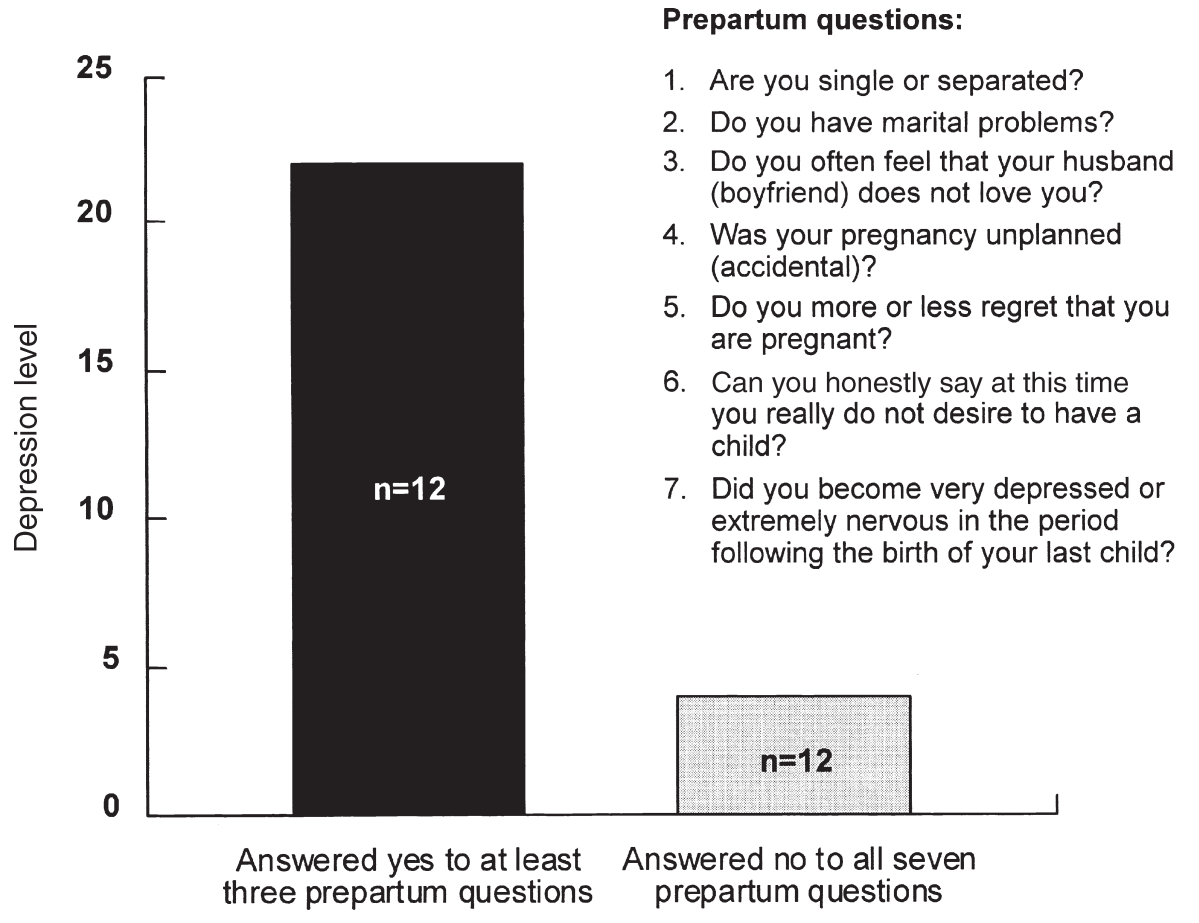

FIGURE 1. Prepartum factors that predict postpartum depression (data from Field et al. 1985).

weeks later. If the father's scores are an indication of his ability or willingness to invest in childrearing (as is true for mothers; see part II), then these data support a causal relation between paternal support and maternal PPD.

The etiological significance of marital satisfaction is also supported by the prospective study by Gotlib et al. (1991) of PPD among a sample of 730 pregnant women. Women who were not depressed during pregnancy but became depressed postpartum were distinguished from those that did not become depressed postpartum by lower marital satisfaction during pregnancy. It should be emphasized that the difference in marital satisfaction scores was obtained before the onset of depression, when all women in the subsample were not depressed-marital discord preceded the onset of depression. This study also assessed factors involved in the postpartum recovery from depression experienced during pregnancy. Of the women who were depressed during pregnancy, those who recovered postpartum reported significantly greater postpartum marital satisfaction. Similarly, Campbell et al. (1992) found high levels of help from spouses and better interactions with infants to be the only variables associated with remission of PPD.

The study of Field et al. (1985), where a simple questionnaire was administered to a large number of women in the third trimester (Figure 1), also supports a causal relationship between paternal investment and PPD. Questions 1 to 3 address the 
availability and reliability of paternal investment, whereas questions 4 to 6 address the value of the pregnancy to the mother. These are precisely the factors that should most strongly predict a negative affective response to the childrearing endeavor, and in fact they do.

Although a prior history of depression, question 7, is a strong predictor of PPD, this factor is neutral with respect to the defection hypothesis. Many theories of depression, including this one, are consistent with past vulnerability predicting future vulnerability. This predictor therefore will not be addressed in this article.

In summary, women without social support, particularly the father's support, are at significantly increased risk for PPD.

Prediction 2: Low infant viability should predict negative affect. Problems with the baby decrease the mother's fitness benefits (on average) and, therefore, should increase the odds that she will experience negative affect postpartum. As noted earlier, pregnancy and delivery problems are significant predictors of child morbidity and mortality and, therefore, should predict negative affect postpartum. Consistent with these predictions, a number of studies show strong correlations in the expected direction between pregnancy, delivery, and infant problem variables and PPD (Table 2). ${ }^{3}$ As with social support, these correlations do not appear to depend strongly on making a distinction between depressive symptomology and clinical diagnosis. Unfortunately, pregnancy, delivery, and infant complications are presented as aggregate scores, so the correlation of any particular problem with PPD cannot be determined from the literature.

In the study by Hopkins et al. (1987), infants of depressed mothers had experienced significantly greater incidence of neonatal complications than infants of nondepressed mothers (32\% vs. 4\%). O'Hara et al. (1984) found that although a general measure of life events was not a significant predictor of PPD, childcare-related stressors (e.g., baby health problems) and obstetric risk factors accounted for $19 \%$ of the variance in depressive symptomology.

In the study by Campbell and Cohn (1991) of more than 1,000 primiparous middle class mothers of healthy full-term infants, the depressed group reported significantly more complications during pregnancy or delivery than the nondepressed group. A high correlation between pregnancy and delivery problems, and depression

\footnotetext{
${ }^{3}$ Haig (1993) argues that gestational diabetes and pregnancy-induced hyptertension, two important types of pregnancy problems, are fetal strategies to extract additional resources from the mother when circumstances indicate that the father is less likely to invest. If so, their association with PPD may be through the shared variable of social support rather than their association with higher rates of perinatal morbidity and mortality and, therefore, cannot be construed as evidence in favor of the defection hypothesis. An alternate hypothesis is that the fetus may attempt to extract additional resources from the mother to increase its odds of survival when it has information that it is damaged in some way (still assuming a conflict between maternal and paternal genes, of course). This hypothesis would account for the association between gestational diabetes and hypertension, and higher rates of infant morbidity and mortality. Under this scenario, the morbidity and mortality data for these disorders support the defection hypothesis.

In addition to being a significant predictor of child morbidity and mortality, pregnancy-induced hypertension is a leading cause of maternal death (Grimes 1994; Li et al. 1996; Ni and Rossignol 1994; Walker 1996). The apparent association of pregnancy-induced hypertension with PPD therefore may also be evidence in favor of prediction 4: it may be in the mother's interest to invest in her own survival and development rather than the infant. This prediction will not be tested further due to lack of data.
} 
in mothers of apparently healthy infants 1 month or more later is strong evidence for the defection hypothesis. When studies that include only mothers of healthy infants show strong correlations between pregnancy problems and PPD, it implies that this relationship may be due to the existence of a neurophysiological link between these indicators of lowered infant viability and PPD that is independent of the mother's subjective evaluation. This type of functional specialization is a hallmark of adaptation (Williams 1966).

Male PPD also appears to be associated with infant variables in the direction predicted by the defection hypothesis. Atkinson and Rickel (1984) found that, controlling for prepartum depression scores, father's postpartum depression scores were significantly negatively correlated with the perception that the infant was "better than average." Male PPD was also correlated with prepartum expectations of a better than average infant. Thus, men who, prepartum, expected their infants to be above average, but, postpartum, felt their infants to be below average were the most likely to be depressed.

Not all studies support associations with infant problems and PPD (Paykel et al. 1980), and some support an association between less complicated deliveries and PPD (O'Hara et al. 1982; Paykel et al. 1980). The authors of these studies suggest this could be the result of additional support from doctors and family members received by mothers with very complicated deliveries. If doctors, nurses, and other hospital staff assume most of the costs of caring for a seriously impaired infant, while they and family members also provide the mother with high levels of support, the mother's very low costs may not exceed her benefits, and she will therefore have little reason to experience PPD. These last two studies notwithstanding, there is clear evidence that both infant problems and reliable indicators of infant problems are significantly associated with PPD.

To my knowledge, poor infant temperament, usually categorized as an "infant problem" in most studies of PPD, is not an indicator of decreased infant viability. However, it is associated with increased costs to the mother-colicky babies can be exhausting. Poor infant temperament should therefore also be significantly correlated with PPD. In a meta-analysis of 17 studies on the relationship between infant temperament and PPD, Beck (1996a) found a significant positive correlation of moderate effect size.

Prediction 3: poor environments should predict negative affect. If mothers do not have sufficient resources to raise a new infant or the environment is exceptionally hazardous, they should consider defecting, saving their investment for existing or future offspring, or for their own health and welfare. Low levels of resources or a hazardous environment should therefore predict negative affect postpartum. Because it is not clear how modern environmental stressors such as poverty and crime relate to environmental stressors of ancestral environments, this article will not closely examine these variables. Nevertheless, some evidence supports the association of poverty and poor environments with PPD. Although most studies find little or no correlation of PPD with socioeconomic status (SES) or other demographic variables (Cutrona 1982; O'Hara and Zekoski 1988), this is probably because subjects are obtained from fairly homogenous middle class populations. In those few 
Table 4. Cross-Cultural Studies of Postpartum Depression

\begin{tabular}{|c|c|c|c|}
\hline Study & Ethnic groups & Sample size & Correlates and other findings \\
\hline $\begin{array}{l}\text { Areias et al. } \\
\quad 1996\end{array}$ & $\begin{array}{l}\text { Oporto, } \\
\quad \text { Portugal }\end{array}$ & $\begin{array}{l}\text { Longitudinal study of } 54 \\
\text { women and } 42 \\
\text { husbands }\end{array}$ & $\begin{array}{l}\text { Women: reduced social support } \\
\text { Husbands: Low social class, poor } \\
\text { social adjustment, PPD in wife. High } \\
\text { prevalence rates compared to similar } \\
\text { studies in the U.S. and England. }\end{array}$ \\
\hline Cox 1983 & $\begin{array}{l}\text { Ugandan and } \\
\text { Scottish } \\
\text { women }\end{array}$ & $\begin{array}{c}183 \text { of } 263 \text { pregnant, rural } \\
\text { Ugandan women were } \\
\text { assessed postpartum }\end{array}$ & $\begin{array}{l}\text { Some differences in symptom profiles } \\
\text { between the two populations. }\end{array}$ \\
\hline $\begin{array}{l}\text { Ghubash and } \\
\text { Abou-Saleh } \\
1997\end{array}$ & $\begin{array}{c}\text { United Arab } \\
\text { Emirates }\end{array}$ & & $\begin{array}{l}\text { Prepartum marital problems, postpartum } \\
\text { marital problems, unwanted } \\
\text { pregnancy, unwanted baby, baby's } \\
\text { health, life events, lack of social } \\
\text { support (e.g., housemaid), and } \\
\text { previous psychiatric history. }\end{array}$ \\
\hline Harkness 1987 & $\begin{array}{l}\text { Rural } \\
\text { Kipsigis, } \\
\text { Kenya }\end{array}$ & Sample size $=10$ & $\begin{array}{l}\text { No PPD (probably due to low sample } \\
\text { size). }\end{array}$ \\
\hline $\begin{array}{l}\text { Ifabumuyi and } \\
\text { Akindele } \\
1985\end{array}$ & $\begin{array}{l}\text { Northern } \\
\text { Nigeria }\end{array}$ & $\begin{array}{l}\text { Review of } 50 \text { cases of } \\
\text { psychiatric disturbance }\end{array}$ & \\
\hline $\begin{array}{l}\text { Jinadu and } \\
\text { Daramola } \\
1990\end{array}$ & $\begin{array}{l}\text { Yoruba in } \\
\text { Nigeria }\end{array}$ & $\begin{array}{l}400 \text { prepartum, } 348 \\
\text { postpartum }\end{array}$ & $\begin{array}{l}\text { Very high rates of complaints prepartum; } \\
\text { lower rates postpartum. }\end{array}$ \\
\hline $\begin{array}{l}\text { Park and } \\
\quad \text { Dimigen } \\
1995\end{array}$ & $\begin{array}{l}\text { Korean } \\
\text { immigrants } \\
\text { to Scotland }\end{array}$ & $\begin{array}{l}105 \text { Korean mothers and } \\
52 \text { Scottish mothers }\end{array}$ & $\begin{array}{l}\text { Higher rates of PPD among the Koreans; } \\
\text { higher rates of somatic complaints } \\
\text { among the Koreans; equal rates of } \\
\text { psychological complaints. }\end{array}$ \\
\hline $\begin{array}{l}\text { Shimizu and } \\
\text { Kaplan } 1987\end{array}$ & $\begin{array}{l}\text { Japan and the } \\
\text { U.S. }\end{array}$ & $\begin{array}{l}29 \text { Japanese; } 21 \\
\text { Americans }\end{array}$ & $\begin{array}{l}\text { Social isolation predicts PPD for } \\
\text { Americans but not Japanese. Only } \\
\text { traditional role concept predicts PPD } \\
\text { for Japanese women. }\end{array}$ \\
\hline $\begin{array}{l}\text { Stewart and } \\
\text { Jambunathan } \\
1996\end{array}$ & $\begin{array}{l}\text { Hmong } \\
\text { immigrants } \\
\text { to the U.S. }\end{array}$ & $\begin{array}{l}52 \text { Hmong women from } \\
\text { northeastern and } \\
\text { central Wisconsin }\end{array}$ & $\begin{array}{l}\text { Symptoms look very similar to PPD, } \\
\text { despite authors' protestations to the } \\
\text { contrary. }\end{array}$ \\
\hline $\begin{array}{l}\text { Thorpe et al. } \\
1992\end{array}$ & $\begin{array}{l}\text { Britain and } \\
\text { Greece }\end{array}$ & 65 Greek; 101 British & $\begin{array}{l}\text { Lack of social support and life events } \\
\text { both correlate with PPD. }\end{array}$ \\
\hline $\begin{array}{l}\text { Upadhyaya et } \\
\text { al. } 1989\end{array}$ & $\begin{array}{l}\text { Asian } \\
\text { immigrants } \\
\text { to England }\end{array}$ & $\begin{array}{l}75 \text { Asian subjects; } 75 \\
\text { English subjects }\end{array}$ & $\begin{array}{l}\text { No difference in relative proportion of } \\
\text { somatic vs. psychological symptoms } \\
\text { between the two groups. Same } 4 \\
\text { items predict case status for both } \\
\text { groups ( } 2 \text { somatic; } 2 \text { psychological). }\end{array}$ \\
\hline $\begin{array}{l}\text { Watson and } \\
\text { Evans } 1986\end{array}$ & $\begin{array}{l}\text { Bengali } \\
\text { immigrants } \\
\text { to England }\end{array}$ & $\begin{array}{l}28 \text { Bengali immigrants, } \\
24 \text { English-speaking } \\
\text { non-Bengali } \\
\text { immigrants, } 49 \\
\text { indigenous English }\end{array}$ & $\begin{array}{l}\text { Objective measure of PPD appears to } \\
\text { agree with both the interviewer's } \\
\text { subjective opinion and the mother's } \\
\text { self-assessment for all three groups. }\end{array}$ \\
\hline $\begin{array}{l}\text { Yoshida et al. } \\
1997\end{array}$ & $\begin{array}{l}\text { Japanese } \\
\text { immigrants } \\
\text { to England }\end{array}$ & $\begin{array}{l}98 \text { mothers at } 3 \text { months } \\
\text { postpartum }\end{array}$ & $\begin{array}{l}\text { Stressful life events and obstetric } \\
\text { difficulty but without grandmothers' } \\
\text { support predict PPD. }\end{array}$ \\
\hline
\end{tabular}

$\mathrm{PPD}=$ postpartum depression . 
studies specifically examining financially impoverished populations, rates of PPD are significantly elevated (Hobfoll et al. 1995; Seguin et al. 1995; Zelkowitz and Milet 1995).

More specifically, Warner et al. (1996) found both maternal unemployment and "head of household" unemployment to be significant risk factors for PPD. Finally, in a large study, Cooper et al. (1996) report that $7 \%$ of mothers with PPD were dissatisfied with the area they were living in (prepartum) compared to only $3 \%$ of nondepressed mothers. Thus, poor environments do appear to predict negative affect postpartum.

Prediction 4: PPD should be universal. If PPD is an adaptation, then all women in all cultural contexts should experience PPD if circumstances warrant. This does not imply that PPD should be found in all societies, however. If, in some particular society, all women receive sufficient social support, do not face social costs for defecting from low-viability offspring, and otherwise incur few costs when raising offspring, then rates of PPD should be extremely low. Nevertheless, if PPD is rarely encountered in non-Western populations, or if it is not correlated with low levels of social support or low infant viability, then the adaptationist account offered here is seriously undermined. Some women in most societies are expected to have faced the problem of insufficient social support or deciding whether to invest in low viability offspring. These problems are inevitable, and it is unlikely that most societies will have solved these problems to the complete satisfaction of all mothers.

Although studies of PPD in populations other than middle class Caucasian Americans and British are few, the syndrome has been identified in a number of different ethnic contexts (see Table 4 for a summary of cross-cultural studies of PPD). As required by the defection hypothesis, PPD does correlate with low levels of social support (Areias et al. 1996; Ghubash and Abou-Saleh 1997; Thorpe et al. 1992; Yoshida et al. 1997) and low infant viability (Ghubash and Abou-Saleh 1997; Yoshida et al. 1997). Unfortunately, studies in small, kin-based societies that are most likely to resemble ancestral social environments are essentially nonexistent.

Prediction 5: PPD is not a hormonal byproduct. Perhaps the most common preconception about PPD is that it is a maladaptive byproduct of the substantial changes in hormone levels associated with the puerperium. Although hormonal correlations with PPD would neither support nor refute the defection hypothesis, as there must be some biochemical correlates of psychological states, correlations are a prerequisite for any hormonal byproduct hypothesis. Interestingly, changes in progesterone, estrogen, prolactin, and cortisol levels appear to have surprisingly little to do with PPD (Harris 1994; O'Hara 1995). Additionally, fathers-who are not undergoing dramatic hormonal changes-experience PPD at $50 \%$ to $100 \%$ the rate of mothers (O’Hara 1985; Richman et al. 1991).

The relationship between postpartum thyroid dysfunction and PPD may support a "hormonal" etiology for a small number of cases of PPD. The results of Pop et al. (1991), as well as the work of Harris et al. (1992) and Pederson et al. (1993), clearly demonstrate that thyroid dysfunction is associated with a small but signifi- 
cant fraction of PPD. ${ }^{4}$ Nevertheless, in light of the strong associations of PPD with social support and infant variables, and its frequent occurrence in fathers, a strictly hormonal etiology for most cases of PPD is untenable.

Other correlates and noncorrelates. Most studies find a strong correlation between either a previous history of emotional problems, depression, or depression during pregnancy, and PPD (Atkinson and Rickel 1984; Cutrona and Troutman 1986; Gotlib et al. 1991; Graff et al. 1991; Logsdon et al. 1994; O’Hara et al. 1983, 1984; Whiffen 1988; Whiffen and Gotlib 1993). Unfortunately, the defection hypothesis does not clearly illuminate this important aspect of PPD.

Most demographic variables are not reliably associated with PPD. These include age (Campbell and Cohn 1991; Gotlib et al. 1989, 1991), marital status (Gotlib et al. 1991), occupational level (Campbell and Cohn 1991), work status (Campbell and Cohn 1991; Gotlib et al. 1989, 1991), the sex of the infant (Campbell and Cohn 1991), the number of children in the home (Gotlib et al. 1989, 1991; $c f$. O'Hara 1986), and education (Gotlib et al. 1989, 1991; cf. Campbell and Cohn 1991; O'Hara 1986). The expected correlations between PPD and age will be discussed later. No strong correlation is expected with marital status, as this merely represents the formal status of a mother's relationship and not the presence or absence of an investing mate. Whereas the occupational level, work status, and education of the mother might be expected to predict availability of resources and thus PPD, the relationship of these variables to resources is ambiguous at best. If the mother has a low occupational or educational level but her husband has a high occupational level, then the mother's access to resources will be sufficient. Two incomes from low occupational levels also might be sufficient. As noted earlier, financially impoverished populations do appear to experience higher levels of PPD, and maternal unemployment (as opposed to housewife status) and head-of-household unemployment have both been found to be risk factors for PPD.

Number of children in the home and sex of the infant are both potentially evolutionarily significant variables, but the data reported in existing studies do not allow tests of hypotheses regarding differential investment based on sex or number of existing offspring. The (unreported) age distribution of the existing children would be critical for evaluating the costs and benefits they represent to the mother. In ancestral environments, infants represented significantly higher costs and lower benefits (due to high rates of infant mortality) than did older children. Children of different sexes also can have different relative values to the mother when resource availability varies (Trivers and Willard 1973), and thus, in conjunction, are possible predictors of PPD, but this hypothesis cannot be assessed with existing data.

This concludes part one of the article. There is strong evidence that circumstances that would have represented increased fitness costs to mothers in ancestral environments are etiological factors for negative affect—sad or depressed moodin modern mothers. Mother's sad or depressed mood may function analogously to Haig 1993). 
physical pain to inform her that she is suffering or has recently suffered a serious fitness cost and, as will be explained in the next section, motivate her to reduce this cost.

\section{THE DEFECTION HYPOTHESIS, PART TWO: REDUCE COSTS}

This section presents a functional hypothesis for the second major symptom of PPD: loss of interest. If a mother's sad or depressed mood informs her that she has suffered a reproductive cost, then it is possible that she will act to reduce this cost to allocate her finite resources to more beneficial ventures, consistent with PI theory. We should therefore expect mothers with PPD to frequently experience a loss of interest in the infant. Consistent with this expectation, loss of interest in the infant is a prominent symptom of PPD (APA 1994; Beck 1992, 1996b; Campbell et al. 1992). Not only do mothers with PPD often lose interest in their child, they frequently have thoughts of harming them (Jennings et al., in press). Loss of interest in the infant is not the only strategy mothers have to reduce their costs, however. Conceivably, they may decide to direct a greater proportion of their time and energy toward their infant by losing interest in other activities like caring for older children, caring for other family members, doing household chores, and working. Anecdotal evidence for this hypothesis is illustrated in an interview with a depressed mother (Beck 1996b:102):

When I was going through the depression real bad, I pushed away my daughter and my husband. It was like I just wanted to take care of the baby and I didn't want to take care of anyone else. I could only deal with one person, and the rest of you should go away, 'cause I can't deal with the rest of it.

Beck notes that mothers in her study were unable to cope with more than one child at a time, resented their older children, and pushed them away. Because older children are more likely to survive with reduced maternal investment than are newborns, mothers with a viable offspring or an offspring with reversible health problems may opt to focus their efforts on the baby if they can count on the husband or relatives taking care of the other children. Similarly, mothers may have to reduce their investment in their husbands to focus all their effort on the newborn. Thus, when mothers have a healthy baby and a supportive mate, but also have significant and time-consuming responsibilities like caring for other young children, family members, their mate, or producing income, they may defect from these other responsibilities to invest in the newborn. Excessive noninfant-related responsibilities also may predict PPD, with loss of interest applying to activities other than infant care.

Although PPD may be an adaptation to defect from any costly activity during the puerperium, a focus on loss of interest in the infant is warranted because this symptom is likely to have the greatest detrimental effect on child development, a serious negative consequence of PPD (Murray 1992; Whiffen and Gotlib 1989).

Many women with PPD are unable to feel any joy or love in taking care of their infants, and often they have obsessional thoughts about harming them (APA 1994; Beck 1992, 1996b; Jennings et al., in press), symptoms that are clearly consistent 
with a desire to defect. Similarly, "negative emotions while with the baby" are significantly correlated with PPD (Affonso and Arizmendi 1986), as are "negative or detached feelings for the baby" (Kumar and Robson 1984).

The in-depth interviews by Beck (1996b) with 12 women suffering from PPD provide a powerful portrayal of these mothers' experiences with, and attitudes toward, their infants that is entirely consistent with the defection hypothesis:

I had no control of my own self-being, nothing, mind, soul, nothing. It [PPD] basically controlled me. I wanted to reach out to my baby, yet I couldn't (p. 100).

The fact that I couldn't love her normally made the guilt even worse. You just don't feel anything good for your baby. You just feel full of guilt (p. 101).

I just went through the motions making sure my baby was fed. I was just like a robot. I would pick her up. I would breastfeed her. I would put her down. I was just walking around the house like a zombie (p. 100).

I would be going along and being okay, and then I would get up to that changing table and in a matter of seconds my mind would have started with, 'Oh, the baby is going to fall off the table. I don't care if she falls off the table.' Why did I think that I don't care if she falls off the table? Of course I care (p. 102).

Beck distilled nine themes from the interview transcripts, each consistent with the defection hypothesis:

Theme 1: Postpartum depression overtook mother's minds and bodies, preventing them from reaching out to their infants and depriving them of any feelings of joy.

Theme 2: Overwhelmed by the responsibilities for caring for their children, the women were petrified that they would not be able to cope.

Theme 3: To survive, some mothers erected a wall to separate themselves emotionally and physically from their children.

Theme 4: Stripped of a strong desire to interact with their children and plagued by oversensitivity to stimuli, mothers often failed to respond to their infants' cues.

Theme 5: Guilt and irrational thinking pervaded mothers' minds during their day-today interactions with their children. [Guilt suggests that mothers are not doing as much for their children as they feel they should; "irrational thinking" may refer to infanticidal ideation or to exaggerated fears about the infant.]

Theme 6: Uncontrollable anger erupted periodically toward the children, to the degree that mothers feared they might harm their children. [A possible infanticide adaptation.]

Theme 7: As postpartum depression engulfed the mothers, they perceived that detrimental relationships with their older children were materializing. [These mothers may be investing in the infant at the expense of their older children.]

Theme 8: Feelings of loss enveloped the mothers as they dwelled on their relationships with their children. [This theme may be most consistent with the arguments presented for negative affect in section one.]

Theme 9: Striving to minimize the negative effects of postpartum depression on their children, mothers attempted to put their children's needs above their own. [In the same way that people can continue with an activity even though it causes them physical pain, they can decide to continue an activity that causes psycho- 
logical pain. This theme also suggests that mothers are "aware" of the tradeoff between investing in themselves and investing in their infants, a core concept of PI theory.]

If PPD is, in part, an adaptation to motivate women to reduce investment in their offspring under certain conditions, then women who did not want to be pregnant in the first place should be at higher risk for PPD. This is, in fact, the case. Field et al. (1985) found that an affirmative prepartum response to questions like "was your pregnancy unplanned?," "do you regret being pregnant?," "can you say that you do not desire to have a child?" (in addition to other questions, see Figure 1) significantly distinguished women with PPD from those without. Similarly, Campbell et al. (1992) found that not being happy about the pregnancy distinguished women with PPD from those without. Finally, Kumar and Robson (1984) found that women with PPD had significantly more often considered an abortion.

Although PPD is defined primarily by affective and cognitive symptoms, if it is an adaptation to reduce investment in offspring, then it must have, on average, actually modified ancestral mothers' behavior in a way that prevented them from attaching to or investing in their infants. The meta-analysis of Beck (1995) of 19 studies on the effects of PPD on mother-infant interactions (total number of dyads $=829$ ) indicates that PPD has a moderate to large negative effect on maternal-infant interaction. In these studies, observers who are blind to the mothers' depression status rate her interaction with her infant. Mothers with PPD are observed to have significantly increased disengagement, negative affect, flatness of affect, irritation, tenseness, annoyance, and intrusiveness toward the infant on the one hand, and significantly less warmth, delight, positive regard, sensitivity, activity, contented facial expressions, imitative behaviors, contingent responses, and game-playing on the other. In addition to exhibiting more negative emotions and fewer positive emotions toward their infants, mothers with PPD are less responsive and less sensitive to infant cues, have failed to attain a successful maternal role, and have infants that are less securely attached (Beck 1995, 1996b; Cohn et al. 1990, 1991; Field et al. 1985; Fowles 1996; Hoffman and Drotar 1991; Murray 1991; Murray and Cooper 1996). By being less responsive and less sensitive to infant cues, mothers with PPD are clearly mothering less.

These studies indicate that mothers with PPD are ambivalent about their pregnancies, have difficulty emotionally investing in, and interacting with, their infants, and are less sensitive and responsive to their infants. These manifestations of PPD strongly support the "loss of interest" and "reduced investment" in the infant predicted by the defection hypothesis.

Whereas loss of interest in the infant has a straightforward interpretation in the context of PI theory, loss of interest in virtually all important life activities presents a more difficult although perhaps more important theoretical problem. Some possible adaptive functions for this symptom vis-à-vis evolutionarily significant risks and dangers of the puerperium will be offered in the next section. These more speculative functions extend the "defection" hypothesis to renegotiation or defection from relations with the father and family members in an attempt to solve two problems: 
increase the levels of investment of others, or reduce the social costs of defecting from childrearing.

\section{THE DEFECTION HYPOTHESIS, PART THREE: NEGOTIATION}

Why, if caring for a newborn or engaging in other activities is not in a mother's reproductive interest, does she not simply stop engaging in the offending task? Why does she experience the distress of depression with its numerous attendant symptoms? Because a significant fraction of depressions experienced postpartum are minor (Whiffen 1992), most mothers with PPD may in fact only experience a few symptoms consistent with "low mood." The psychological pain hypothesis well accounts for these cases. However, a significant fraction of cases of PPD are major depressions. For example, in their study of 1,033 new mothers, Campbell and Cohn (1991) found that among women with clinically diagnosed depression, 38\% had major depression, 31\% had "probable" major depression, and 31\% had minor depression. The Diagnostic and Statistical Manual (DSM) IV (APA 1994:386) lists the following symptoms of a major depressive episode (a functional hypothesis has been, or will be, offered for symptoms in bold):

\section{Sad or depressed affect}

2. Marked loss of interest in virtually all activities

3. Significant weight loss or gain

4. Hypersomnia or insomnia

5. Psychomotor retardation or agitation

6. Fatigue or loss of energy

7. Feelings of worthlessness or guilt

\section{Diminished ability to think or concentrate}

\section{Recurrent thoughts of death.}

So far, this article has presented a functional argument for symptom 1, and a partial argument for symptom 2-a loss of interest in particular, as opposed to virtually all, activities. These two symptoms would have delivered benefits to ancestral mothers with a low-viability infant or who lacked sufficient social support; when they appear in isolation, or with only one or two other symptoms, they are consistent with a minor depression. The data strongly support the view that minor postpartum depression is an adaptation.

If these other symptoms of major depression are adaptations, then they must have delivered benefits to ancestral mothers, yet they seem designed to prevent the acquisition of benefits. A marked loss of interest in virtually all activities, significant weight loss, hypersomnia, psychomotor retardation, fatigue or loss of energy, and a diminished ability to think or concentrate would all have impeded ancestral mothers from engaging in critical, beneficial activities unrelated to childrearing, such as food gathering and consumption, buffering food shortages, personal hygiene, avoiding environmental hazards, information gathering, or helping relatives and friends. The costs of these symptoms could easily have outweighed the benefits of the first two symptoms, 
seriously undermining the argument that major PPD may be an adaptation. The hypothesis I will explore here is that major depression prevents individuals from acquiring benefits by design. The extraordinarily distressing symptoms of major depression, almost universally interpreted as pathological, may in fact be functional.

Psychological pain theorists have suggested that individuals who have recently suffered a "social injury" should devote time to evaluating the causes of this injury before embarking on new social ventures (Alexander 1986; Nesse 1991; Nesse and Williams 1995; Thornhill and Thornhill 1989, 1990; Tooby and Cosmides 1990). They argue that "lack of interest" may function to prevent an individual from engaging in new social ventures before fully evaluating the failure of the previous social venture. However, I do not find this argument persuasive in accounting for the symptomology of major depression (a syndrome that most evolutionary researchers on depression do not view as an adaptation in any case, e.g., McGuire and Troisi 1998). First of all, a diminished ability to think or concentrate and hypersomnia are precisely the opposite of what one would expect if individuals were attempting to evaluate a recent social failure-individuals should devote considerable thought to, and concentrate on, the failure, not be prevented from doing so by depression. Second, whereas individuals would be expected to devote additional time to evaluating a recent social failure at the expense of pursuing new social ventures, they would not be expected to put their physical health at risk. Psychomotor retardation, a marked loss of interest in virtually all activities, fatigue and loss of energy, weight loss, and hypersomnia would have endangered the lives of individuals living in small, hunter-gatherer groups by impeding their efforts to feed, care for, and protect themselves. It is difficult to see how a symptom like significant weight loss can have any utility vis-à-vis evaluating a social failure.

Psychological adaptations evolved to extract information from the environment that was relevant to reproductive problems, and to then generate behaviors, that, on average, solved these problems. Mothers with insufficient social support and/or a costly infant faced two major problems: how to negotiate increased investment from others, or how to avoid the severe social costs they may have faced if they neglected or killed their offspring. Just as mothers are unlikely to automatically invest in every newborn, fathers and family members are unlikely to automatically invest either. New mothers wishing to raise their infant may then face the problem of negotiating levels of investment from each of these interested parties. If other members of the mother's social environment have the potential to invest more, the mother may be able to elicit more investment than she is currently receiving, making the childrearing venture profitable. She should not immediately abandon the child without first seeing if she can negotiate greater levels of investment.

I argue that major PPD may be a strategy to negotiate greater investment from the father and kin, or to reduce the mother's costs, by functioning somewhat like a labor strike (for a similar view, see Watson and Andrews, unpublished). In a labor strike, workers withhold their own labor to force management to either increase their wages and benefits, or reduce their workload. Similarly, mothers with PPD may be withholding their investment in the new and existing offspring or, in cases of very severe depression, putting at risk their ability to invest in future offspring by 
not taking care of themselves. This may force the father and kin to increase their investment and/or allow the mothers to reduce their levels of investment.

Trivers' theory of reciprocal altruism (Trivers 1971) and later work on the evolution of cooperation that it inspired (for a review, see Axelrod and Dion 1988) help provide a more general formulation of the "labor strike" analogy. Like the relationship between a worker and her boss, the human pair bond is a cooperative ventureboth the mother and father agree to participate in the mutually fitness-enhancing endeavor of childrearing. As models of the evolution of cooperation make clear (Axelrod and Hamilton 1984), individuals will evolve to provide benefits to others only if they are free to defect from these activities (e.g., quit) should their costs outweigh their benefits. If the costs of childrearing outweigh the benefits, mothers (and fathers) will need to defect from this costly endeavor-they will need to stop investing in the offspring. The ability to defect from costly endeavors is a key component of any cooperative enterprise. Nonkinship-based reciprocity cannot evolve or be maintained in the population if individuals do not have the ability to defect (Axelrod and Dion 1988; Axelrod and Hamilton 1984), a result with the disturbing implication that child neglect and abandonment are necessary for the evolution and maintenance of cooperative childrearing.

What if an individual cannot easily defect? Evolutionary models suggest that cooperative contracts can be enforced by imposing costs on those who defect. In the U.S. and many other countries, women face extremely high social costs for defecting from their offspring, for example. Due to the social costs, a mother cannot defect from childrearing even if she has no social support or the infant has problems, that is, even if her benefits are significantly outweighed by her costs. Women who do defect from childrearing may face serious criminal charges.

In ancestral environments, mothers also may have faced high social costs for defecting. Both the father and other family members had a fitness interest in the offspring, and, rather than investing themselves, they may have attempted to coerce the mother into providing the child care by threatening her with social costs should she neglect the offspring (Figueredo and McCloskey 1993). Because the mother's production of offspring also was critical to maintaining or increasing the size of the group and thus its political power vis-à-vis other groups (Paige and Paige 1981), unrelated group members may have been motivated to coerce the mother as well. The mother then was trapped between a rock and a hard place: she could not afford to invest in the offspring, and she could not afford to defect either. This was an extraordinarily costly situation for the mother, and extraordinary efforts to negotiate greater investment, or to find some way to minimize the costs of defecting, are called for. PPD may be, in part, an adaptation to socially imposed constraints on female reproductive decision-making.

What power does the mother have to negotiate greater investment? I argue that major depression and its attendant symptoms, such as the loss of interest in most or all activities, significant weight loss, hypersomnia, psychomotor retardation, fatigue and loss of energy, and a diminished ability to think or concentrate, have at least three negotiating functions. The first function is analogous to a worker who threatens to quit or go on strike in an effort to negotiate a larger salary. Mothers, as key in- 
vestors in new, existing, and future offspring, are a valuable source of benefits and can negotiate greater investment by putting these benefits at risk. By losing interest in herself, a depressed mother is making a very credible threat of defecting from cooperative endeavors that others find reproductively beneficial. She is not providing the benefits to others that she has previously agreed to provide and is putting her ability to provide such benefits at risk. By holding important benefits hostage (e.g., the life of the newborn, investment in existing offspring, and her ability to produce future offspring) the mother may be able to elicit greater investment from others. The threat of defection is credible and robust to bluff-calling, because the mother's costs are currently outweighing her benefits.

Second, if mothers fail to negotiate greater investment, they may suffer social costs for defecting, but the imposition of social costs is not free. Those who impose social costs (e.g., the father and family members) will have to decide whether to continue to pay the costs of coercion when they are not generating much return-the depressed mother is clearly willing to not care for herself rather than continue to invest in the offspring. The father and family members may decide that it is not worth it to continue to attempt to coerce the mother and let her defect. This outcome is probably rare, because mothers are likely to be successful in negotiating increased investment and thus do not ultimately abandon or neglect their offspring.

Finally, because depression prevents the mother from pursuing other profitable opportunities, it may mitigate the social costs of defecting. Those who defect from social contracts - those who cheat - are often punished. Receiving a benefit without providing a benefit in return is perceived by most people as a very reliable cue of cheating (Cosmides and Tooby 1992). Mothers with major depression are not providing benefits, but they are not receiving or pursuing them either. This may "shortcircuit" cheater detection mechanisms, thereby reducing the likelihood of being punished, a possibility that probably requires some constraint on the evolution of cheater-detection mechanisms.

Although data supporting a negotiating function for PPD are few, they do uphold the main outlines of the hypothesis. For example, women who report that their partners are overcontrolling in the marriage have an elevated risk of PPD, especially when levels of investment are low (Boyce et al. 1991; Schweitzer et al. 1992). In a similar vein, Leathers et al. (1997) found that new mothers who felt that they did not have control either in the parenting role or at work also experienced high levels of postpartum depressive symptomology. In other words, when husbands or bosses attempt to impose constraints on mothers' actions, mothers are more likely to experience depression, as predicted by the defection hypothesis. This effect is especially marked when the husbands also fail to provide investment. Furthermore, family members of women with PPD report that they are more attentive to the mother's needs as a consequence of her depression, and that they have assumed many of her responsibilities. They also report that their increased investment is a considerable burden and that arguments are common, suggesting conflict and negotiation over who should do what (Boath et al. 1998). Finally, as predicted, recovery from PPD is associated with higher levels of spousal support (Campbell et al. 1992).

This functional defection hypothesis does not account for a few symptoms, 
particularly significant weight gain (energy storage for rough times ahead?), insomnia (spend time thinking about critical problems instead of sleeping?), and psychomotor agitation. Feelings of worthlessness are consistent with low investment by others, or with the unwillingness of others to renegotiate social contracts. Feelings of guilt are consistent with a desire to change or defect from one's existing social contracts. Suicidal threats may represent the ultimate threat of defection. Individuals who threaten or attempt suicide may be attempting to extort those who benefit from their association with the afflicted individual (Watson and Andrews, unpublished). Whereas an evolutionary analysis of these remaining symptoms, and, indeed, a careful test of part three of the defection hypothesis, is beyond the scope of this article, I hope I have provided at least the reasonable expectation that such an analysis may be fruitful, and that the hypothesis of depression as a credible threat of defection merits consideration. This proposed negotiating function for major PPD does not replace the psychological pain hypothesis but in fact requires it. To negotiate by threatening to defect, mothers still need to know when their costs are exceeding their benefits, and they still need to be motivated to reduce their costs.

\section{WHY NOT BE NICE?}

The defection hypothesis does not imply that mothers are precluded from using "nice" strategies for negotiating increased investment. If they have received cues that such strategies are likely to be successful, mothers may just ask for increased investment, perhaps in exchange for concessions in other areas or for promising to provide future benefits, or perhaps because the welfare of the child is at stake and it is in the interest of both parents to invest more. A threat of defection should only be used when there is a serious conflict between the degree of investment that the mother feels she needs, and the levels that the father and/or other family members are willing to provide-workers can be nice, work hard, and still not make enough money.

Serious conflicts of this nature will not be uncommon. It is likely that, for most couples, the period of cohabitation prior to pregnancy involves negotiating the terms of biparental care: who is expected to do what for the family. Once the baby is born and the mother is nursing and unable to pursue other mating opportunities, the father may be tempted to unilaterally change the terms of the mateship by, for example, seeking other mates, especially if he has doubts about the paternity of the newborn or if new mating opportunities have presented themselves. Mothers are therefore expected to be especially sensitive to cues that the father intends to divert his investment elsewhere. ${ }^{5}$ On the other hand, the infant has just spent 9 months inside the mother, and the mother may be (unconsciously) privy to information about infant quality that is not accessible to the husband or other family members, and thus be less inclined to provide the levels of investment that others think she ought.

In ancestral environments, biparental care was a high-stakes game, and serious conflicts of interest were undoubtedly frequent. Far from being a weakness, it is possible that PPD may best be viewed as a potent, evolved strategy for leveraging

${ }^{5}$ I thank Margo Wilson and Martin Daly for pointing this out. 
the considerable power mothers had over their own reproductive value and the value of their children once "nice" strategies had failed.

\section{IS PPD A SIGNAL OF NEED?}

Several researchers have argued that depression is a social signal (Henderson 1974; Price et al. 1994; Watson and Andrews, unpublished). Whereas Price et al. view depression as a signal of submission after losing a social competition, Watson and Andrews argue, among other things, that depression is a signal of need, an idea first seriously pursued by Henderson and collaborators (Henderson 1974, 1977, 1978, 1981; Henderson et al. 1980). Note that Henderson and colleagues view need as the low quantity and quality of social relationships, whereas Watson and Andrews conceptualize need as a set of socially imposed constraints on the pursuit of fitnessenhancing activities, similar to the defection hypothesis. Depression as a signal of need is both consistent with, and complementary to, the defection hypothesis. Negotiating by going on strike will be completely ineffective if no one realizes that a strike is in progress, for example. Furthermore, if mothers can elicit investment by signaling need to interested parties like the father, they should do so. In this regard, it is interesting to note that tearfulness is a prominent symptom of PPD (APA 1994:386). The costs incurred by depressed mothers speak eloquently to the legitimacy of their plight as well (Watson and Andrews, unpublished).

Signals of need are expected to be particularly effective when the fitness interests of the signal recipients coincide with the fitness interests of the signaler. However, when there are genuine conflicts of interest between, for example, a mother and father over levels of investment in offspring, signaling by the mother is unlikely to elicit greater investment by her husband. It is in these circumstances that the power to withhold benefits must be exercised in an attempt to negotiate better terms.

\section{THE CASE OF DEPRESSION IN GENERAL}

As the editor of a recent volume on depression has noted about this affliction, "[d]espite a great deal of thorough research there is no agreement concerning the etiology, symptomatology, and treatment methods" (Wolman 1990). Even diathesisstress models that appear to well characterize both PPD and depression in general (O'Hara 1995) beg several questions, including (1) what types of events count as "stress" and why, and (2) why do stressful events provoke the particular set of symptoms involved in depression as opposed to any other set of symptoms? Why does stress not provoke anger or fear or relief? Why should there be psychomotor retardation, loss of interest, or loss of energy? An evolutionary approach is ideal for pursuing these levels of explanation and thus has much to offer the current debate and research on the definition and nature of stress and the psychological symptoms it provokes (see also Thornhill and Furlow 1998). For the functional hypothesis presented here, "stress" would be defined as evolutionarily costly events or situations like lack of social support and infant problems. It should not apply to events that do not impose evolution- 
arily significant costs. In this regard it is interesting to note that for the case of PPD, life stress unrelated to either social support (Hopkins et al. 1987) or infant stressors (O'Hara et al. 1984) did not distinguish depressed from nondepressed groups.

If the defection hypothesis can elucidate PPD at the level of function, then perhaps it can elucidate depression in general. Whenever a social strategy has failed, be it a job, marriage, or other important endeavor involving the cooperation of others, individuals should be aware that they have suffered a fitness cost, and they should lose interest and reduce or eliminate their investment in this activity. They should defect. When individuals find that the social costs of defecting are high, that is, when they have little power to renegotiate social contracts, they may stop investing in themselves until these social costs are reduced or investment by others in the venture is increased. This view is consistent with that of Wenegrat (1995), who argues that the high rates of depression among women are a consequence of their relative lack of power in society.

Because PPD occurs predictably among approximately $10 \%$ of a readily identifiable population (i.e., pregnant women), it represents an ideal opportunity to study depression. If PPD is to serve as a model for depression, however, then it should share fundamental similarities with depressive episodes in general. Whiffen (1992) carefully reviewed 24 studies on PPD published between 1964 and 1991 specifically to determine whether PPD differed from depression in any important aspects. It did not. She concluded that research and practice would benefit from abandoning PPD as a distinct diagnosis. In a study specifically designed to determine whether PPD is fundamentally different from general depression, Whiffen and Gotlib (1993) conclude that the primary difference between women with PPD and women without PPD is that PPD woman are less depressed. The data collected in their study do not support the hypothesis that PPD is separate diagnostically from non-PPD. PPD thus appears to be a good model for depression in general. Nevertheless, they concede that other factors, such as family psychiatric history, treatment response, and biological variables, must be considered before a firm conclusion can be reached.

\section{SELF-REPORT METHODOLOGIES}

Most of the evidence in favor of the defection hypothesis cannot be explained as an artifact of biased reporting by depressed mothers. With the exception of maternal perceptions of paternal investment, all important correlates of PPD are supported, at least in part, by objective measures, including hospital charts, researcher ratings of mother-infant interactions, face-to-face interviews and observations, income levels, and unemployment status (Campbell and Cohn 1991; Campbell et al. 1992; Hopkins et al. 1987; Kumar and Robson 1984; O’Hara et al. 1984; Paykel et al. 1980; Warner et al. 1996; Whiffen and Gotlib 1989). The validity of the paternal investment data is supported by longitudinal studies where the maternal perception of paternal support was collected prepartum when the mothers were not depressed (Gotlib et al. 1991) and where the father's mood (assessed by the father's self-report) predicted the mother's future mood (assessed by the mother's self-report). 


\section{FURTHER TESTING OF THE DEFECTION HYPOTHESIS}

Proof of the defection hypothesis will require substantially more data than is currently available. This includes stronger evidence that PPD occurs cross-culturally when conditions warrant; that, in its major forms, it actually does increase the investment of others; and that, in addition to the support and infant variables, low levels of resources, maternal health, and mate quality are etiological factors. Conversely, mothers should not suffer a loss of interest in the infant when the infant is of high viability, when there is sufficient social support and environmental resources for the existing as well as the new offspring, when the mother is in good health, and when her mate is of high quality.

A mother with minor (as opposed to major) PPD should not automatically lose interest in all her children. According to PI theory, loss of interest generally should pertain only to the reproductively least valuable offspring, i.e., either to the new infant or to one or more existing children. Although there will be exceptions to thisthe father leaves after the birth of a second child for example, making it impossible for the mother to raise any offspring-loss of interest should not automatically apply to all children. This represents a potentially sensitive and easy test of the defection hypothesis. If loss of interest in a new infant always implies loss of interest in existing children, the defection hypothesis for minor PPD will be seriously undermined. Reduced investment in existing children, mates, and other activities postpartum clearly warrants further study.

Primiparous women with few future opportunities to conceive present another opportunity to test the defection hypothesis. Older primiparae should be less likely to lose interest in the infant, i.e., defect, because the current infant may be their only chance to reproduce. Possible evidence against this prediction comes from the study of Kumar and Robson (1984): older (30+) primiparae were more likely to experience PPD. Several possibilities may account for this result: 30 may be still too young for this effect to be noticeable, rates in these primiparae may be a consequence of higher rates of depression among older women in the general population, these rates may reflect higher rates of low viability offspring among older women, or these cases of PPD may not have involved loss of interest in the infant. Nevertheless, if this result is replicated for women with few future opportunities to conceive, if the depression is found to be causally related to childbirth (rather than other life events or past history), and if the depression involves loss of interest in the infant, it would weaken the defection hypothesis.

\section{CONCLUSION}

Human reproductive effort is characterized by a very large degree of biparental care. Because human infants require enormous amounts of investment, ancestral mothers needed to carefully assess both the availability of support from the father and family members, and infant viability before committing to several years of nursing and childcare. If a child was unlikely to survive to reproductive age due to lack of sufficient investment or low viability, then it was in the mother's reproductive interest to 
defect from the costly childrearing venture. It is highly unlikely that mothers will blindly invest in all infants without carefully (though perhaps unconsciously) evaluating, at a minimum, levels of support and infant viability.

Consistent with these predictions of PI theory, there is compelling evidence that a perceived lack of support, and problems with the pregnancy, delivery, or infant, are correlated with PPD, regardless of whether one assesses PPD by levels of depressive symptomology or clinical diagnosis. Studies showing that prepartum measures of infant viability and perceived levels of social support (when the mothers are not depressed) predict PPD support the view that infant viability and low levels of social support are etiological factors - they cause PPD. The cognitive, affective, and behavioral manifestations of PPD characterize individuals who have suffered a cost, experience that cost negatively, are motivated to reduce that cost, and act on their motivations. Mothers with PPD mother less. In sum, the evidence suggests that PPD may be an adaptation that functions to inform mothers that they have suffered a reproductive cost, and that successfully motivates them to reduce this cost by reducing or eliminating maternal investment postpartum. These data for PPD strongly support the psychological pain hypothesis. Several symptoms of PPD, especially in its major form, do not appear consistent with the psychological pain hypothesis, however. These symptoms have the effect of preventing the mother from providing a wide range of benefits to either herself or to others. Given that two major adaptive problems faced by mothers during the puerperium are to either elicit investment from others or to avoid the imposition of social costs, and that credible threats of defection from social contracts are an effective negotiating tactic, major depression thus may be viewed as an adaptation to elicit greater investment or to reduce the mother's investment while avoiding social costs by making just such a credible threat of defection. PPD may be, in part, an adaptation to attempts by others to constrain and control female reproductive decision-making.

Although the data presented may be consistent with hypotheses and theoretical approaches to PPD not discussed in this article, they do suggest that the defection hypothesis deserves serious consideration as a possible explanation for certain aspects of this affliction. Because many researchers argue that there is little to distinguish PPD from depression occurring at other times (O'Hara and Zekoski 1988; Watson et al. 1984; Whiffen 1991, 1992; Whiffen and Gotlib 1993), any conclusion reached for PPD also may be applicable to depression in general. The ability to defect from costly ventures has obvious utility, and many researchers argue that this ability is one of the foundations of cooperative behavior-cooperation cannot evolve if individuals have no means to renegotiate or terminate costly relationships (for a review, see Axelrod and Dion 1988). If depression is a strategy that humans use to renegotiate or defect from costly social relationships, it would be significant in understanding the evolution of cooperation.

The puerperium is an ideal venue for studying the evolution of social cognition, because parents predictably encounter costs and benefits that are both large and well defined from an evolutionary perspective. Furthermore, the data described herein provide solid evidence that at least one category of puerperal decision-making adheres closely to evolutionary expectations. 
I would like to gratefully acknowledge Peggy La Cerra for suggesting that postpartum depression would provide an interesting test of my theory of depression, and for many useful conversations; Don Symons for his usual enlightening criticisms, suggestions, and editorial efforts; Leda Cosmides, John Tooby, and the Center for Evolutionary Psychology lab group for their guidance and critique; Paul Watson, Paul Andrews, Russell Gardner, Andy Thomson, and John Pearce for a stimulating email exchange on the possible adaptive functions of depression - the exchanges with Paul Watson, who has a similar theory of depression, were particularly inspiring and helpful; Martin Daly, Margo Wilson, Jason Feldman, Sabrina Grannan, Aurelio Figueredo, Nicole Hess, Beth Kirsner, and several anonymous reviewers for their careful readings and numerous helpful suggestions; and Jeanne Bracker, whose clinical insight underlies much that is written here. Portions of this paper were presented at the Human Behavior and Evolution Society Annual Meeting, Northwestern University, Evanston, Illinois, June 1996.

\section{REFERENCES}

Acien, P. A comparative study on breech deliveries attended in 1992: hospital centers from Latin America versus Spain and Portugal. European Journal of Obstetrics, Gynecology, and Reproductive Biology 67:9-15, 1996.

Affonso, D.D., and Arizmendi, T.G. Disturbances in post-partum adaptation and depressive symptomatology. Journal of Psychosomatic Obstetrics and Gynaecology 5:15-32, 1986.

Affonso, D.D. and Domino, G. Postpartum depression: a review. Birth: Issues in Perinatal Care and Education 11:231-235, 1984.

Alexander, R.D. Ostracism and indirect reciprocity: the reproductive significance of humor. Ethology and Sociobiology 7:253-270, 1986.

Ananth, C.V., Savitz, D.A., and Bowes, W.A., Jr. Hypertensive disorders of pregnancy and stillbirth in North Carolina 1988 to 1991. Acta Obstetricia et Gynecologica Scandinavica 74:788-793, 1995.

APA. Diagnostic and Statistical Manual of Mental Disorders. Washington, DC: American Psychiatric Association, 1994.

Areias, M.E.G., Kumar, R., Barros, H., and Figueiredo, E. Correlates of postnatal depression in mothers and fathers. British Journal of Psychiatry 169:36-41, 1996.

Atkinson, A.K., and Rickel, A.U. Postpartum depression in primiparous parents. Journal of Abnormal Psychology 93:115-119, 1984.

Axelrod, R., and Dion, D. The further evolution of cooperation. Science 242:1385-1390, 1988.

Axelrod, R., and Hamilton, W.D. The evolution of cooperation in biological systems. In The Evolution of Cooperation, R. Axelrod (Ed.). New York: Basic Books, Inc., 1984. pp. 88-105.

Barkow, J.H., Cosmides, L., and Tooby, J. (Eds). The Adapted Mind: Evolutionary Psychology and the Generation of Culture. New York: Oxford University Press, 1992.

Beck, C.T. The lived experience of postpartum depression: a phenomenological study. Nursing Research 41: 166-170, 1992.

Beck, C.T. The effects of postpartum depression on maternal-infant interaction: a meta-analysis. Nursing Research 44:298-304, 1995.

Beck, C.T. A meta-analysis of the relationship between postpartum depression and infant temperament. Nursing Research 45:225-230, 1996a.

Beck, C.T. Postpartum depressed mothers' experiences interacting with their children. Nursing Research 45:98-104, 1996b.

Beck, C.T. A meta-analysis of predictions of postpartam depression. Nursing Research 45:297-303, 1996c.

Beischer, N.A., Wein, P., Sheedy, M.T., and Steffen, B. Identification and treatment of women with hyperglycaemia diagnosed during pregnancy can significantly reduce perinatal mortality rates. Australian and New Zealand Journal of Obstetrics and Gynaecology 36:239-247, 1996.

Betzig, L.L., Borgerhoff Mulder, M., and Turke, P. (Eds.). Human Reproductive Behavior: A Darwinian Perspective. Cambridge: Cambridge University Press, 1988.

Birtchnell, J. How Humans Relate. Westport, CT: Paeger, 1993.

Blurton Jones, N. The costs of children and the adaptive scheduling of births: Towards a sociobiological perspective on demography. In Sociobiology of Sexual and Reproductive Strategies. A. Rasa, C. Vogel, and E. Voland (Eds.). New York: Chapman and Hall, 1989, pp. 265-282. 
Boath, E.H., Pryce, A.J., and Cox, J.L. Postnatal depression: the impact on the family. Journal of Reproductive and Infant Psychology 16:199-203, 1998.

Bongaarts, J., and Delgado, H. Effects of nutritional status on fertility in rural guatemala. In Natural Fertility, H. Leridon and J. Menken (Eds.). Liége: Ordina Editions. 1979, pp. 107-133.

Boyce, P., Hickie, I., and Parker, G. Parents, partners or personality? Risk factors for post-natal depression. Journal of Affective Disorders 21:245-255, 1991.

Campbell, S.B., and Cohn, J.F. Prevalence and correlates of postpartum depression in first-time mothers. Journal of Abnormal Psychology 100:594-599, 1991.

Campbell, S.B., Cohn, J.F., Flanagan, C., Popper, S., and Meyers, T. Course and correlates of postpartum depression during the transition to parenthood. Development and Psychopathology 4:29-47, 1992.

Chisholm, J.S. Death, hope, and sex: life-history theory and the development of reproductive strategies. Current Anthropology 34:1-24, 1993.

Clutton-Brock, T.H. The Evolution of Parental Care. Princeton, NJ: Princeton University Press, 1991.

Cohn, J.F., Campbell, S.B., Matias, R., and Hopkins, J. Face-to-face interactions of postpartum depressed and nondepressed mother-infant pairs at 2 months. Developmental Psychology 26:15-23, 1990.

Cohn, J.F., Campbell, S.B., and Ross, S. Infant response in the still-face paradigm at 6 months predicts avoidant and secure attachment at 12 months. Special Issue: Attachment and developmental psychopathology. Development and Psychopathology 3:367-376, 1991.

Collins, N.L., Dunkel-Schetter, C., Lobel, M., and Scrimshaw, S.C. Social support in pregnancy: psychosocial correlates of birth outcomes and postpartum depression. Journal of Personality and Social Psychology 65:1243-1258, 1993.

Cosmides, L., and Tooby, J. Cognitive adaptations for social exchange. In The Adapted Mind: Evolutionary Psychology and the Generation of Culture, L. Cosmides, J.H. Barkow, and J. Tooby (Eds.). New York: Oxford University Press, 1992. pp. 163-228.

Cox, J.L. Postnatal depression: a comparison of African and Scottish women. Social Psychiatry 18:2528,1983

Cox, J.L., Murray, D., and Chapman, G. A controlled study of the onset, duration and prevalence of postnatal depression. British Journal of Psychiatry 163:27-31, 1993.

Cox, J.L., Holden, J.M., and Sagovsky, R. Detection of postnatal depression: development of the 10-item Edinburgh Postnatal Depression Scale. British Journal of Psychiatry 150:782-786, 1987.

Cramer, B. Are postpartum depressions a mother-infant relationship disorder? Infant Mental Health Journal 14:283-297, 1993.

Cutrona, C. E. Nonpsychotic postpartum depression: a review of recent research. Clinical Psychology Review 2:487-503, 1982.

Cutrona, C.E. Causal Attributions and perinatal depression. Journal of Abnormal Psychology 92:161$172,1983$.

Cutrona, C.E., and Troutman, B.R. Social support, infant temperament, and parenting self-efficacy: a mediational model of postpartum depression. Child Development 57:1507-1518, 1986.

Daly, M., and Wilson, M. Discriminative parental solicitude: a biological perspective. Journal of Marriage and the Family 42:277-288, 1980.

Daly, M., and Wilson, M. Sex, Evolution, and Behavior. Belmont, CA: Wadsworth Publishing Company, 1983.

Daly, M., and Wilson, M. A sociobiological analysis of human infanticide. In Infanticide: Comparative and Evolutionary Perspectives. G. Hausfater and S.B. Hrdy (Eds.). New York: Aldine, 1984, pp. 487-502.

Daly, M., and Wilson, M. The Darwinian Psychology of Discriminative Parental Solicitude. Paper presented at the Nebraska Symposium on Motivation, Lincoln, Nebraska, 1987.

Daly, M., and Wilson, M. Homicide. New York: Aldine de Gruyter, 1988.

Daly, M., and Wilson, M. Discriminative parental solicitude and the relevance of evolutionary models to the analysis of motivational systems. In The Cognitive Neurosciences, M.S. Gazzaniga (Ed.). Cambridge, MA: The MIT Press, 1995, pp. 1269-1286.

de Courcy-Wheeler, R.H., Wolfe, C.D., Warburton, F., Goodman, J., Reynolds, F., and Gamsu, H. The association between small size for gestational age and perinatal and neonatal death in a UK Regional Health Authority. Paediatric and Perinatal Epidemiology 9:431-440, 1995.

Dickemann, M. Female infanticide, reproductive strategies, and social stratification: a preliminary model. In Evolutionary Biology and Human Social Behavior, N.A. Chagnon and W. Irons (Eds.). North Scituate, MA: Duxbury Press, 1979, pp. 321-367.

Dickemann, M. Paternal confidence and dowry competition: a biocultural analysis of purdah. In Natural 
Selection and Social Behavior: Recent Research and New Theory, R.D. Alexander and D.W. Tinkle (Eds.). New York: Chiron Press, 1981, pp. 417-438.

Draper, P., and Harpending, H. Father absence and reproductive strategy. Journal of Anthropological Research 38:255-273, 1982.

Field, T., Sandburg, S., Garcia, R., Vega-Lahr, N., Goldstein, S., and Guy, L. Pregnancy problems, postpartum depression, and early mother-infant interactions. Developmental Psychology 21:1152$1156,1985$.

Figueredo, A.J., and McCloskey, L.A. Sex, money, and paternity: the evolutionary psychology of domestic violence. Ethology and Sociobiology 14:353-379, 1993.

Fowles, E.R. Relationships among prenatal maternal attachment, presence of postnatal depressive symptoms, and maternal role attainment. Journal of the Society of Pediatric Nurses 1:75-82, 1996.

Gardner, R.J. Mechanisms in major depressive disorder: an evolutionary model. Archives of General Psychiatry 39:1436-1441, 1982.

Ghubash, R., and Abou-Saleh, M.T. Postpartum psychiatric illness in Arab culture: prevalence and psychosocial correlates. British Journal of Psychiatry 171:65-68, 1997.

Gilbert, P. Human Nature and Suffering. London: Lawrence Erlbaum Associates, 1989.

Gotlib, I.H., Whiffen, V.E., Mount, J.H., Milne, K., and Cordy, N.I. Prevalence rates and demographic characteristics associated with depression in pregnancy and the postpartum. Journal of Consulting and Clinical Psychology 57:269-274, 1989.

Gotlib, I.H., Whiffen, V.E., Wallace, P.M., and Mount, J.H. Prospective investigation of postpartum depression: factors involved in onset and recovery. Journal of Abnormal Psychology 100:122132, 1991.

Graff, L.A., Dyck, D.G., and Schallow, J.R. Predicting postpartum depressive symptoms: a structural modelling analysis. Perceptual and Motor Skills 73:1137-1138, 1991.

Grimes, D.A. The morbidity and mortality of pregnancy: still risky business. American Journal of Obstetrics and Gynecology 170:1489-1494, 1994.

Gupta, V., Bhatia, B.D., and Mishra, O. P. Meconium stained amniotic fluid: antenatal, intrapartum and neonatal attributes. Indian Pediatrics 33:293-297, 1996.

Hagen, E.H. Postpartum depression as an adaptation to paternal and kin exploitation. Paper presented at the Human Behavior and Evolution Society 8th Annual Conference, Northwestern University, 1996.

Hagen, E.H. The Defection Hypothesis vs. the Niche Hypothesis of Major Depression. Paper presented at the ASCAP Annual Meeting, University of California, Davis, 1998a.

Hagen, E.H. The Functions of Postpartum Depression and the Implications for General Depression. Paper presented at the Human Behavior and Evolution Society 10th Annual Conference, University of California, Davis, 1998 b.

Hagen, E.H. Reproductive Decision-Making and Postpartum Depression. Paper presented at the 97th Annual Meeting of the American Anthropological Association, Philadelphia, Pennsylvania, 1998c.

Hagen, E.H. Parental investment and child health in a Yanomamö village. (Submitted).

Haig, D. Genetic conflicts in human pregnancy. Quarterly Review of Biology 68:495-532, 1993.

Hames, R. Costs and benefits of monogamy and polygyny for Yanomamö women. Ethology and Sociobiology 17:181-199, 1996.

Harkness, S. The cultural mediation of postpartum depression. Medical Anthropology Quarterly 1:194209, 1987.

Harris, B. Biological and hormonal aspects of postpartum depressed mood: working towards strategies for prophylaxis and treatment. Special Issue: Depression. British Journal of Psychiatry 164:288-292, 1994

Harris, B., Othman, S., Davies, J.A., Weppner, G.J., Richards, C.J., Newcombe, R.G., Lazarus, J.H., Parkes, A.B., Hall, R., and Phillips, D.I. Association between postpartum thyroid dysfunction and thyroid antibodies and depression. British Medical Journal 305:152-156, 1992.

Hartung, J. Polygyny and inheritance of wealth. Current Anthropology 23:1-12, 1982.

Hartung, J. Matrilineal inheritance. Behavioral and Brain Sciences 8:661-688, 1985.

Hawthorne, G., Snodgrass, A., and Tunbridge, M. Outcome of diabetic pregnancy and glucose intolerance in pregnancy: an audit of fetal loss in Newcastle General Hospital 1977-1990. Diabetes Research and Clinical Practice 25:183-190, 1994.

Henderson, S. Care-eliciting behavior in man. Journal of Nervous Mental Disorders 159:172-181. 1974.

Henderson, S. The social network, support and neurosis. British Journal of Psychiatry 131:185-191, 1977. 
Henderson, S. Social bonds in the epidemiology of neurosis: a preliminary communication. British Journal of Psychiatry 132:463-466, 1978.

Henderson, S. Social relationships, adversity and neurosis: an analysis of prospective observations. British Journal of Psychiatry 138:391-398, 1981.

Henderson, S., Byrne, D.G., Duncan-Jones, P., Scott, R., and Adcock, S. Social relationships, adversity and neurosis: a study of associations in a general population sample. British Journal of Psychiatry 136:574-583, 1980.

Hill, K., and Kaplan, K. Tradeoffs in male and female reproductive strategies among the Ache. In Human Reproductive Behavior: A Darwinian perspective, L. Betzig, M. Borgerhoff Mulder, and P. Turke (Eds.). Cambridge: Cambridge University Press, 1988, pp. 277-306.

Hobfoll, S.E., Ritter, C., Lavin, J., Hulsizer, M.R., and Cameron, R.P. Depression prevalence and incidence among inner-city pregnant and postpartum women. Journal of Consulting and Clinical Psychology 63:445-453, 1995.

Hoffman, Y., and Drotar, D. The impact of postpartum depressed mood on mother-infant interaction: like mother like baby? Infant Mental Health Journal 12:65-80, 1991.

Hopkins, J., Campbell, S.B., and Marcus, M. Role of infant-related stressors in postpartum depression. Journal of Abnormal Psychology 96:237-241, 1987.

Hopkins, J., Marcus, M., and Campbell, S.B. Postpartum depression: a critical review. Psychological Bulletin 95:498-515, 1984.

Hrdy, S.B. Infanticide among animals: A review, classification, and examination of the implications for the reproductive strategies of females. Ethology and Sociobiology 1:13-40. 1979.

Hrdy, S.B. Fitness tradeoffs in the history and evolution of delegated mothering with special reference to wet-nursing, abandonment, and infanticide. Ethology and Sociobiology 13:409-442, 1992.

Ifabumuyi, O.I., and Akindele, M.O. Post-partum mental illness in Northern Nigeria. Acta Psychiatrica Scandinavica 72:69-73, 1985.

Jennings, K.D., Ross, S., Popper, S., and Elmore, M. Thoughts of harming infants in depressed and nondepressed mothers. Journal of Affective Disorders (in press).

Jinadu, M.K., and Daramola, S.M. Emotional changes in pregnancy and early puerperium among the Yoruba women of Nigeria. International Journal of Social Psychiatry 36:93-98, 1990.

Kumar, R., and Robson, K.M. A prospective study of emotional disorders in childbearing women. British Journal of Psychiatry 144:35-47, 1984.

Lampert, A., and Friedman, A. Sex differences in vulnerability and maladjustment as a function of parental investment: an evolutionary approach. Social Biology 39:65-81, 1992.

Lancaster, J.B. Human adolescence and reproduction: an evolutionary perspective. In School-Age Pregnancy and Parenthood: Biosocial Dimensions, J.B. Lancaster and B.A. Hamburg (Eds.). New York: Aldine De Gruyter, 1986, pp. 17-37.

Leathers, S.J., Kelley, M.A., and Richman, J.A. Postpartum depressive symptomatology in new mothers and fathers: parenting, work, and support. Journal of Nervous and Mental Disease 185:129_ 139, 1997.

Li, X.F., Fortney, J.A., Kotelchuck, M., and Glover, L.H. The postpartum period: the key to maternal mortality. International Journal of Gynaecology and Obstetrics 54:1-10, 1996.

Logsdon, M.C., McBride, A.B., and Birkimer, J.C. Social support and postpartum depression. Research in Nursing and Health 17:449-457, 1994.

Mann, J. Nurturance or negligence: maternal psychology and behavioral preference among preterm twins. In The Adapted Mind: Evolutionary Psychology and the Generation of Culture, J. H. Barkow, L. Cosmides, and J. Tooby (Eds.). Oxford: Oxford University Press, 1992. pp. 367390.

McGuire, M.T., and Troisi, A. Darwinian Psychiatry. New York: Oxford University Press, 1998.

Miller, J.E., and Huss-Ashmore, R. Do reproductive patterns affect maternal nutritional status? An analysis of maternal depletion in Lesotho. American Journal of Human Biology 1:409-419, 1989.

Murray, L. Intersubjectivity, object relations theory, and empirical evidence from mother-infant interactions. Special Issue: The effects of relationships on relationships. Infant Mental Health Journal 12:219-232, 1991.

Murray, L. The impact of postnatal depression on infant development. Journal of Child Psychology and Psychiatry and Allied Disciplines 33:543-561, 1992.

Murray, L., and Cooper, P.J. The impact of postpartum depression on child development. International Review of Psychiatry 8:55-63, 1996.

Nesse, R. What good is feeling bad-the evolutionary benefits of psychic pain. Sciences 31:30-37, 1991. 
Nesse, R.M., and Williams, G.C. Why Do We Get Sick?: The New Science of Darwinian Medicine. New York: Times Books, 1995.

Ni, H., and Rossignol, A.M. Maternal deaths among women with pregnancies outside of family planning in Sichuan, China. Epidemiology 5:490-494, 1994.

O'Hara, M.W. Depression and marital adjustment during pregnancy and after delivery. American Journal of Family Therapy 13:49-55, 1985.

O'Hara, M.W. Social support, life events, and depression during pregnancy and the puerperium. Archives of General Psychiatry 43:569-573, 1986.

O’Hara, M.W. Postpartum Depression: Causes and Consequences. New York: Springer-Verlag, 1995.

O'Hara, M.W., Neunaber, D.J., and Zekoski, E. M. Prospective study of postpartum depression: prevalence, course, and predictive factors. Journal of Abnormal Psychology 93:158-171, 1984.

O'Hara, M.W., Rehm, L.P., and Campbell, S.B. Predicting depressive symptomatology: cognitivebehavioral models and postpartum depression. Journal of Abnormal Psychology 91:457-461, 1982.

O’Hara, M.W., Rehm, L.P., and Campbell, S.B. Postpartum depression: a role for social network and life stress variables. Journal of Nervous and Mental Disease 171:336-341, 1983.

O'Hara, M.W., and Swain A.M. Rates and risk of postpartum depression - A meta-analysis. International Review of Psychiatry 8:37-54, 1996.

O’Hara, M.W., and Zekoski, E.M. Postpartum depression: a comprehensive review. In Motherhood and Mental Illness, R. Kumar and I.F. Brockington (Eds.). London: Wright, 1988, pp. 17-63.

Omu, A.E., al-Othman, S., al-Qattan, F., al-Falah, F.Z., and Sharma, P. A comparative study of obstetric outcome of patients with pregnancy induced hypertension: economic considerations. Acta Obstetricia et Gynecologica Scandinavica 75:443-448, 1996.

Paige, K.E., and Paige, J.M. The Politics of Reproductive Ritual. Berkeley, CA: University of California Press, 1981.

Park, E.-H.M., and Dimigen, G. A cross-cultural comparison: postnatal depression in Korean and Scottish mothers. Psychologia 38:199-207, 1995.

Paykel, E.S., Emms, E.M., Fletcher, J., and Rassaby, E.S. Life events and social support in puerperal depression. British Journal of Psychiatry 136:339-346, 1980.

Pedersen, C.A., Stern, R.A., Pate, J., Senger, M.A., Bowes, W.A., and Mason, G.A. Thyroid and adrenal measures during late pregnancy and the puerperium in women who have been major depressed or who become dysphoric postpartum. Special Issue: Toward a new psychobiology of depression in women. Journal of Affective Disorders 29:201-211, 1993.

Pop, V.J., de Rooy, H.A., Vader, H. L., Van der Heide, D., van Son, M., Komproe, I.H., Essed, G.G., and de Geus, C.A. Postpartum thyroid dysfunction and depression in an unselected population. New England Journal of Medicine 324:1815-1816, 1991.

Price, J., Sloman, L., Gardner, R., Gilbert, P., and Rohde, P. The social competition hypothesis of depression. British Journal of Psychiatry 164:309-315, 1994.

Richman, J.A., Raskin, V.D., and Gaines, C. Gender roles, social support, and postpartum depressive symptomatology: the benefits of caring. Journal of Nervous and Mental Disease 179:139-147, 1991.

Roff, D.A. The Evolution of Life Histories: Theory and Analysis. New York: Chapman and Hall, 1992.

Schieber, B., O'Rourke, K., Rodriguez, C., and Bartlett, A. Risk factor analysis of peri-neonatal mortality in rural Guatemala. Bulletin of the Pan American Health Organization 28:229-238, 1994.

Schweitzer, R.D., Logan, G.P., and Strassberg, D. The relationship between marital intimacy and postnatal depression. Australian Journal of Marriage and Family 13:19-23, 1992.

Scorza, W.E. Intrapartum management of breech presentation. Clinics in Perinatology 23:31-49, 1996.

Seguin, L., Potvin, L., St.-Denis, M., and Loiselle, J. Chronic stressors, social support, and depression during pregnancy. Obstetrics and Gynecology 85:583-589, 1995.

Shimizu, Y.M., and Kaplan, B.J. Postpartum depression in the United States and Japan. Journal of CrossCultural Psychology 18:15-30, 1987.

Slavin, M., and Kriegman, D. The Adaptive Design of the Human Psyche: Psychoanalysis, Evolutionary Biology, and the Therapeutic Process. New York: Guilford Press, 1992.

Stearns, S.C. The Evolution of Life Histories. Oxford: Oxford University Press, 1992.

Stewart, S., and Jambunathan, J. Hmong women and postpartum depression. Health Care for Women International 17:319-330, 1996.

Symons, D. The Evolution of Human Sexuality. New York: Oxford University Press, 1979.

Thornhill, N.W., and Thornhill, R. An evolutionary analysis of psychological pain following rape. 1. The effects of victims age and marital status. Ethology and Sociobiology 11:155-176, 1990.

Thornhill, R., and Furlow, B. Stress and human reproductive behavior: attractiveness, women's sexual 
development, postpartum depression, and baby's cry. In Stress and Behavior, A.P. Moller, M. Milinski, and P.J.B. Slater (Eds.). San Diego, CA: Academic Press, 1998, pp. 319-369.

Thornhill, R., and Thornhill, N.W. The evolution of psychological pain. In Sociobiology and the Social Sciences, R.W. Bell and N.J. Bell (Eds.). Lubbock, TX: Texas Tech University Press, 1989, pp. 73-103.

Thorpe, K.J., Dragonas, T., and Golding, J. The effects of psychosocial factors on the emotional wellbeing of women during pregnancy: a cross-cultural study of Britain and Greece. Journal of Reproductive and Infant Psychology 10:191-204, 1992.

Tooby, J., and Cosmides, L. The past explains the present: emotional adaptations and the structure of ancestral environments. Ethology and Sociobiology 11:375-424, 1990.

Upadhyaya, A., Creed, F., and Upadhyaya, M. Psychiatric morbidity among mothers attending well-baby clinic: a cross-cultural comparison. Acta Psychiatrica Scandinavica 81:148-151, 1990.

Voland, E. Human sex-ratio manipulation: historical data from a German parish. Journal of Human Evolution 13:99-107, 1984.

Walker, J.J. Care of the patient with severe pregnancy induced hypertension. European Journal of Obstetrics, Gynecology, and Reproductive Biology 65:127-35, 1996.

Warner, R., Appleby, L., Whitton, A., and Faragher, B. Demographic and obstetric risk factors for postnatal psychiatric morbidity. British Journal of Psychiatry 168:607-611, 1996.

Watson, E., and Evans, S.J. An example of cross-cultural measurement of psychological symptoms in post-partum mothers. Social Science and Medicine 23:869-874, 1986.

Watson, J.P., Elliott, S.A., Rugg, A.J., and Brough, D.I. Psychiatric disorder in pregnancy and the first postnatal year. British Journal of Psychiatry 144:453-462, 1984.

Watson, P., and Andrews, P. An evolutionary theory of unipolar depression as an adaptation for overcoming constraints of the social niche (unpublished).

Weiss, P.A., Kainer, F., Haeusler, M.C., Purstner, P., and Urasch, R. A rapid method for diabetes screening in pregnancy. Geburtshilfe und Frauenheilkunde 54:697-701, 1994.

Weissman, M.M., Bruce, M.L., Leaf, P.J., Florio, L.P., and Holzer, C. Affective disorders. In Psychiatric Disorders in America, L.N. Robins and D.A. Regier (Eds.). New York: Macmillan, Inc, 1991, pp. 53-80.

Wenegrat, B. Illness and Power. New York: New York University Press, 1995.

Whiffen, V.E. Vulnerability to postpartum depression: a prospective multivariate study. Journal of Abnormal Psychology 97:467-474, 1988.

Whiffen, V.E. The comparison of postpartum with non-postpartum depression: a rose by any other name. Journal of Psychiatry and Neuroscience 16:160-165, 1991.

Whiffen, V.E. Is postpartum depression a distinct diagnosis? Clinical Psychology Review 12:485-508, 1992.

Whiffen, V.E., and Gotlib, I.H. Infants of postpartum depressed mothers: temperament and cognitive status. Journal of Abnormal Psychology 98:274-279, 1989.

Whiffen, V.E., and Gotlib, I.H. Comparison of postpartum and nonpostpartum depression: clinical presentation, psychiatric history, and psychosocial functioning. Journal of Consulting and Clinical Psychology 61:485-494, 1993.

Widdowson, E.M. Changes in the Body and Its Organs during Lactation: Nutritional Implications. Paper presented at the Symposium on Breast Feeding and the Mother, London. 1976.

Wilson, M., and Daly, M. The psychology of parenting in evolutionary perspective and the case of human filicide. In Infanticide and Parental Care, S. Parmigiani and F.S. vom Saal (Eds.). Chur, Switzerland: Harwood Academic Publishers, 1994, pp. 73-105.

Wolman, B.B. Preface. In Depressive Disorders: Facts, Theories, and Treatment Methods, B.B. Wolman and G. Stricker (Eds.). New York: John Wiley and Sons, 1990, pp. xii

Wood, J.W. Dynamics of Human Reproduction: Biology, Biometry, Demography. New York: Aldine De Gruyter, 1994.

Worthington-Roberts, B.S., Vermeersch, J., and Williams, S.R. Nutrition in Pregnancy and Lactation. St. Louis: Mirror/Mosby College Publishing, 1985.

Yoshida, K., Marks, M.N., Kibe, N., Kumar, R., Nakano, H., and Tashiro, N. Postnatal depression in Japanese women who have given birth in England. Journal of Affective Disorders 43:69-77, 1997.

Zelkowitz, P., and Milet, T.H. Screening for post-partum depression in a community sample. Canadian Journal of Psychiatry 40:80-86, 1995. 